Report Title:

\title{
BIMETALLIC NANOCATALYSTS IN MESOPOROUS SILICA FOR HYDROGEN PRODUCTION FROM COAL-DERIVED FUELS
}

Report Type: Final Technical Report

Reporting Period Start Date: 02/16/2009

End Date: 02/15/2013

Principal Author(s): Dr. Debasish Kuila (PI)

Dr. Shamsuddin Ilias (co-PI)

Report Issue Date: June 27, 2013 DOE Award No.: DE-FG26-09NT0008066

Report Number: DE-FG26-09NT0008066

Name and Address of Submitting Organization:

Department of Chemistry

Department of Chemical and Bioengineering

North Carolina A\&T State University

Greensboro, NC 27411

E-mail: $\underline{\text { dkuila@ncat.edu }}$

Tel: ((336) 285-2243; Fax: (336) 334-7124 


\section{DISCLAIMER}

This report was prepared as an account of work sponsored by an agency of the United States Government. Neither the United States Government nor any agency thereof, nor any of their employees, makes any warranty, express or implied, or assumes any legal liability or responsibility for the accuracy, completeness, or usefulness of any information, apparatus, product, or process disclosed, or represents that its use would not infringe privately owned rights. Reference herein to any specific commercial product, process, or service by trade name, trademark, manufacturer, or otherwise does not necessarily constitute or imply its endorsement, recommendation, or favoring by the United States Government or any agency thereof. The views and opinions of authors expressed herein do not necessarily state or reflect those of the United States Government or any agency thereof. 


\section{TABLE OF CONTENTS}

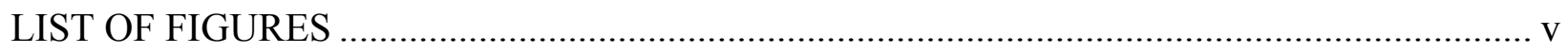

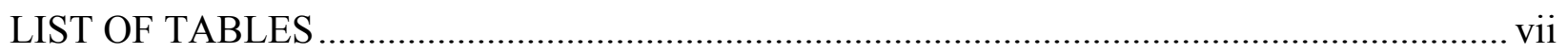

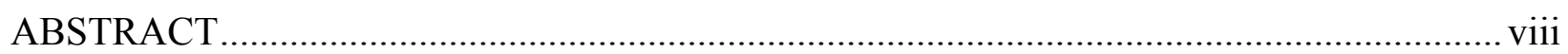

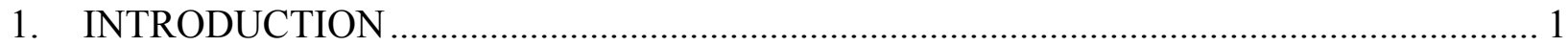

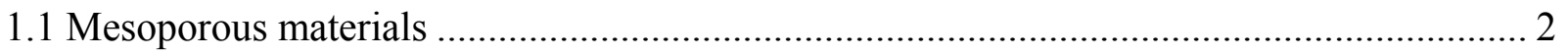

1.1.1 Mesoporous MCM-41 molecular sieves................................................................ 3

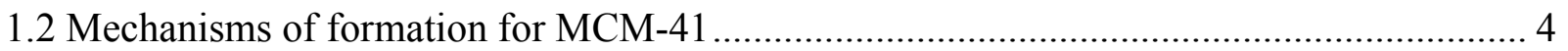

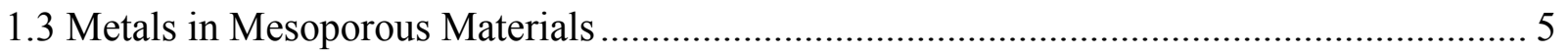

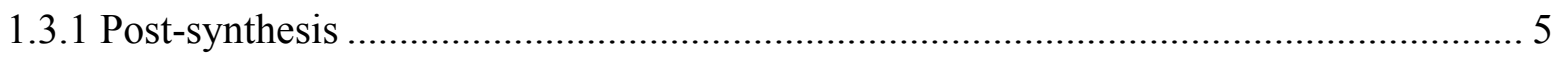

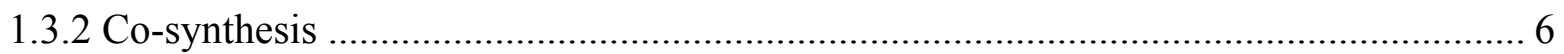

1.4 Template removal from mesoporous silica …………….............................................. 7

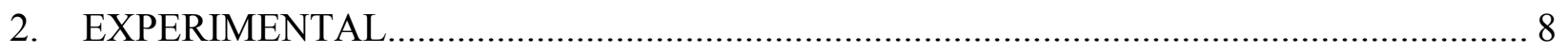

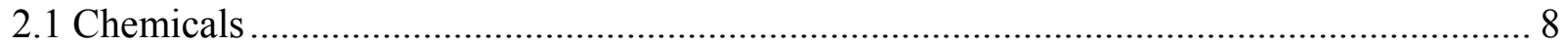

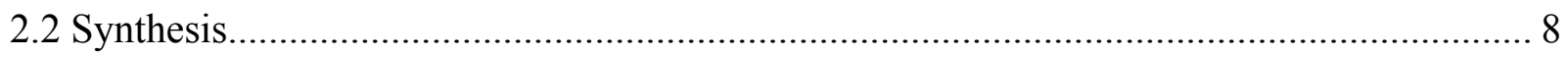

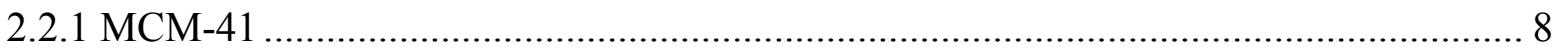

2.2.2 One-pot synthesis of mono- metallic ( $\mathrm{Pd}, \mathrm{Ni} \& \mathrm{Co}$ ) and bi-metallic (Pd-Ni \& Pd-Co)

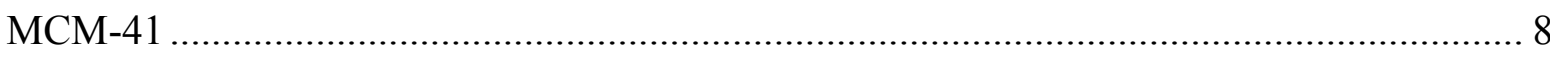

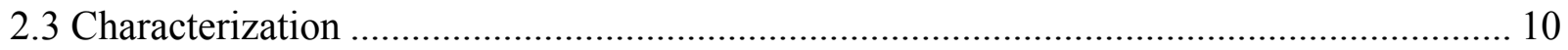

2.3.1 X-ray diffraction (XRD) measurement..................................................................... 10

2.3.2 Nitrogen adsorption/desorption measurement.......................................................... 10

2.3.3 Transmission electron microscopy analysis (TEM) ................................................ 11

2.3.4 Fourier transform infrared spectroscopy measurement (FT-IR) .................................. 11

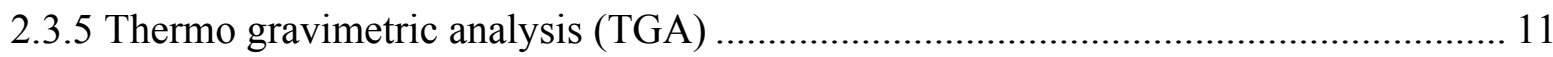

2.4 Steam Reforming of Methanol.................................................................................... 12

2.4.1 Description of the experimental setup ................................................................... 12

2.4.2 Design of the steam reforming reactor ............................................................... 12

2.4.3 Description of the steam reforming of methanol experiment....................................... 13

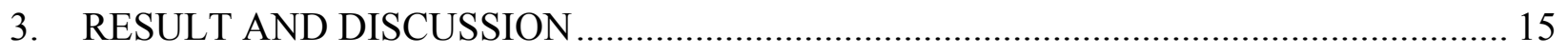

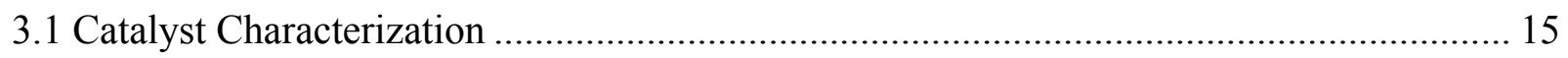

3.1.1 Small angle XRD measurements ......................................................................... 15 


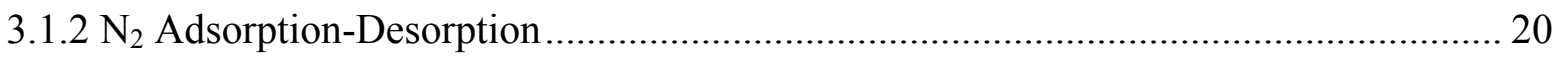

3.1.3 Fourier Transform Infrared Spectra Analyses .................................................... 25

3.1.4 High Resolution Transmission Electron Microscopy (HRTEM) ............................. 29

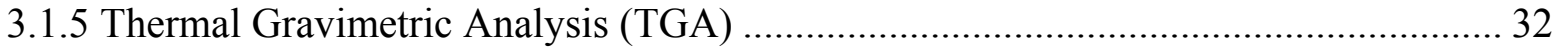

3.2 Catalyst Performance Evaluation for Methanol Steam Reforming................................ 33

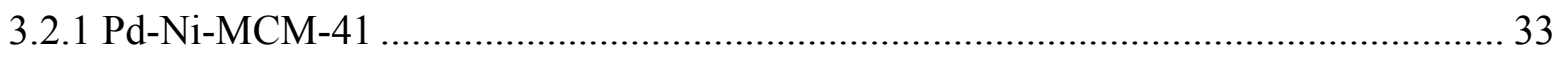

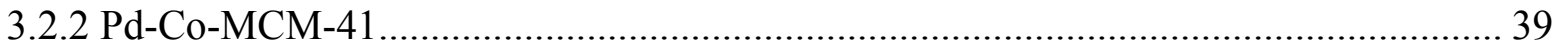

4. CONCLUSION AND RECOMMENDATIONS ........................................................... 42

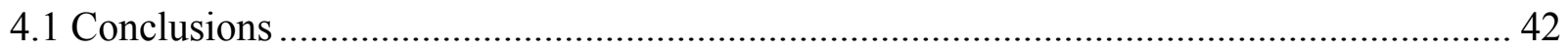

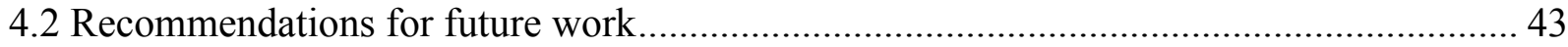

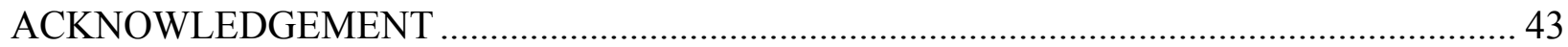

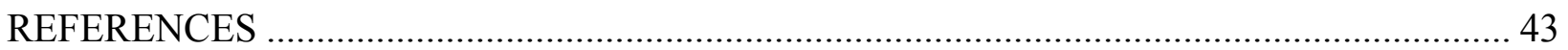




\section{LIST OF FIGURES}

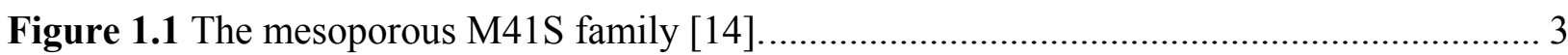

Figure 1.2 (1) Liquid crystal phase initiated and (2) silicate anion initiated MCM-41 Synthesis [14]. 4

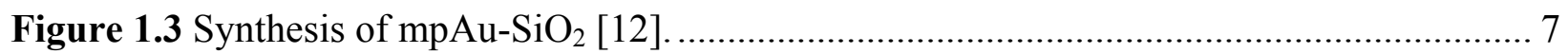

Figure 2.1 Schematic of the steam reforming experimental setup............................................. 14

Figure 2.2 Design of the steam reforming reactor. ................................................................. 15

Figure 3.1 Small-angle XRD patterns of MCM-41 and single-metallic Pd/MCM-41 and $\mathrm{Ni} / \mathrm{MCM} 41$. 16

Figure 3.2 Small-angle XRD pattern of Ni/MCM-41 before and after calcination..................... 17

Figure 3.3 Small-angle patterns of Pd-Ni/MCM-41 (B5) before and after calcination............... 17

Figure 3.4 Small-angle XRD patterns of different Pd-Ni bi-metallic samples........................... 18

Figure 3.5 Small-angle XRD patterns of different Pd-Co-MCM-41samples.............................. 18

Figure 3.6 Nitrogen adsorption-desorption isotherms of calcined (a) Pd/MCM-41, (b) Ni/MCM41, (c) Pd-Ni/MCM-41 (B5) and (d) Pd-Ni/MCM-41 (B6) samples................................ 21

Figure 3.7 The Density Function Theory (DFT) pore size distribution of calcined (a) Pd-MCM41, (b) Ni/MCM-41, (c) Pd-Ni/MCM-41 (B5), (d) Pd-Ni/MCM-41 (B6) ....................... 23

Figure 3.8 $\mathrm{N}_{2}$ adsorption-desorption isotherms of Pd-Ni/MCM-41 (a) as synthesized and (b) calcined samples.

Figure 3.9 The Density Function Theory (DFT) pore size distribution of as-synthesized Pd-Ni(B5) along with Pd-Ni/MCM-41(B5) calcined sample. ................................................... 24

Figure 3.10 FTIR spectrum of MCM-41 after calcination....................................................... 25

Figure 3.11 FTIR spectra of as synthesized and calcined samples of Ni/MCM-41 ................... 27

Figure 3.12 FTIR spectra of as synthesized and calcined Pd-Ni/MCM-41 (B6) samples........... 27

Figure 3.13 FTIR spectra of MCM-41 and Pd-Co-MCM-41 ..................................................... 28

Figure 3.14 TEM images of (a) Pd-Ni/MCM-41 (B1), (b) Pd-Ni/MCM-41 (B2), (c) PdNi/MCM-41 (B5) and (d) Pd-Ni/MCM-41 (B5)....................................................... 29

Figure 3.15 Particle size distribution of Pd-Ni/MCM-41 (B4) ................................................. 30 
Figure 3.16 The EDX spectrum of Pd-Ni/MCM-41 (B4) sample

Figure 3.17 Elemental mapping of Pd-Co-MCM-41 sample........................................................ 32

Figure 3.18 TGA curves of single and bi-metallic MCM-41 material ....................................... 33

Figure 3.19 Effect of reaction temperature on $\mathrm{H}_{2}$ selectivity over Pd/MCM-41, Ni/MCM-41, and $\mathrm{Pd}-\mathrm{Ni} / \mathrm{MCM}-41$ (B1) catalyst in SRM reaction at $\mathrm{H}_{2} \mathrm{O} / \mathrm{CH}_{3} \mathrm{OH}$ mole ratio 3 and at reactant flow rate (a) $0.1 \mathrm{ml} / \mathrm{min}$ (b) $0.2 \mathrm{ml} / \mathrm{min}$ and (3) $0.3 \mathrm{ml} / \mathrm{min}$.......................... 35

Figure 3.20 Effect of temperature on CO selectivity over Pd/MCM-41, Ni/MCM-41, and PdNi/MCM-41 (B1) catalyst in SRM reaction at $\mathrm{H}_{2} \mathrm{O} / \mathrm{CH}_{3} \mathrm{OH}$ mole ratio 3 and at reactant flow rate $0.1 \mathrm{ml} / \mathrm{min}$

Figure 3.21 Effect of temperature on methanol conversion over Pd/MCM-41, Ni/MCM-41, and Pd-Ni/MCM-41 (B1) catalysts in SRM reaction at reactant flow rate (a) 0.1 (b) 0.2 and (c) $0.3 \mathrm{ml} / \mathrm{min}$.

Figure 3.22 Magnetic data for PdNi in mesoporous silica before and after SRM reaction. The lower Inset shows increase of saturation moment at lower temperature.

Figure 3.23 MeOH Conversion using MCM-Co, MCM-Pd, MCM-CoPd (H orB4), MCM-CoPd (L or B6) in SRM reactions; flow rate $0.2 \mathrm{ml} / \mathrm{min}$. 41

Figure 3.24 $\mathrm{H}_{2}$ Selectivity for MCM-Co, MCM-Pd, MCM-CoPd (H or B4), MCM-CoPd (L or B6) in SRM reactions; flow rate, $0.2 \mathrm{ml} / \mathrm{min}$ 41 


\section{LIST OF TABLES}

Table 1.1 Type of M41S mesoporous material.................................................................. 3

Table 2.1 The molar ratio of different metals in the Pd-Co and Pd-Ni-MCM-41 samples ........ 10

Table 2.2 Operating conditions used in steam reforming of methanol.................................... 13

Table 3.1 The d-spacing, cell dimension $\left(a_{0}\right)$ and shrinkage of $d$-spacing before and after calcinations of all the samples.

Table 3.2 Physicochemical characterization of as synthesized and calcined materials of different

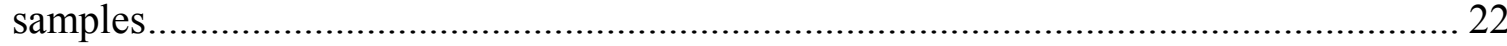

Table 3.3 FT-IR spectra of MCM-41 and M/MCM-41 (M= Pd and Ni)............................... 28 


\begin{abstract}
In steam reforming reactions (SRRs) of alkanes and alcohols to produce $\mathrm{H}_{2}$, noble metals such as platinum $(\mathrm{Pt})$ and palladium $(\mathrm{Pd})$ are extensively used as catalyst. These metals are expensive; so, to reduce noble-metal loading, bi-metallic nanocatalysts containing non-noble metals in MCM-41 (Mobil Composition of Material No. 41, a mesoporous material) as a support material with high-surface area were synthesized using one-pot hydrothermal procedure with a surfactant such as cetyltrimethylammonium bromide (CTAB) as a template. Bi-metallic nanocatalysts of Pd-Ni and Pd-Co with varying metal loadings in MCM-41 were characterized by x-ray diffraction (XRD), $\mathrm{N}_{2}$ adsorption, and Transmission electron microscopy (TEM) techniques. The BET surface area of MCM-41 $\left(\sim 1000 \mathrm{~m}^{2} / \mathrm{g}\right)$ containing metal nanoparticles decreases with the increase in metal loading. The FTIR studies confirm strong interaction between $\mathrm{Si}-\mathrm{O}-\mathrm{M}(\mathrm{M}=\mathrm{Pd}, \mathrm{Ni}, \mathrm{Co})$ units and successful inclusion of metal into the mesoporous silica matrix. The catalyst activities were examined in steam reforming of methanol (SRM) reactions to produce hydrogen. Reference tests using catalysts containing individual metals $(\mathrm{Pd}$, $\mathrm{Ni}$ and $\mathrm{Co}$ ) were also performed to investigate the effect of the bimetallic system on the catalytic behavior in the SRM reactions. The bimetallic system remarkably improves the hydrogen selectivity, methanol conversion and stability of the catalyst. The results are consistent with a synergistic behavior for the Pd-Ni-bimetallic system. The performance, durability and thermal stability of the $\mathrm{Pd}-\mathrm{Ni} / \mathrm{MCM}-41$ and $\mathrm{Pd}-\mathrm{Co} / \mathrm{MCM}-41$ suggest that these materials may be promising catalysts for hydrogen production from biofuels.

A part of this work for synthesis and characterization of Pd-Ni-MCM-41 and its activity for SRM reactions has been published ("Development of Mesoporous Silica Encapsulated Pd-Ni Nanocatalyst for Hydrogen Production" in "Production and Purification of Ultraclean Transportation Fuels"; Hu, Y., et al.; ACS Symposium Series; American Chemical Society: Washington, DC, 2011.)
\end{abstract}




\section{INTRODUCTION}

The hydrogen-based economy is expected to play a major role in meeting future energy needs, lowering dependence on foreign oil. There is a concerted effort in the development of a hydrogen economy. Stringent emission regulation and recent global energy shortage have stimulated research and development in fuel cell area. Ultra pure $\mathrm{H}_{2}$ is required for the proper functionality of proton exchange membrane (PEM) fuel cells.

Coals can be converted into liquid fuels like gasoline or diesel by several different processes. Coal is gasified to produce syngas which is condensed using F-T catalysts to yield methanol and light hydrocarbons [1,2] which are further processed into gasoline and diesel. Gasification of coal is one of the significant routes to produce clean-burning hydrogen for future automobiles and power-generating fuel cells. Methanol produced from syngas via coal gasification can be used for steam reforming reactions (SRRs) to yield $\mathrm{H}_{2}$. Methanol is a primary candidate as a $\mathrm{H}_{2}$ carrier due to its large abundance and can easily be transported and stored for the on-board $\mathrm{H}_{2}$ production system. Moreover, methanol has high atomic ratio of $\mathrm{H} / \mathrm{C}$ and free from sulfur and other impurities and can be activated at relatively low temperature (under 300 ${ }^{\circ} \mathrm{C}$ ) compared to other fuels [3]. The main reactions involved in steam reforming of methanol (SRM) are represented by the following equations:

$$
\begin{array}{lr}
\mathrm{CH}_{3} \mathrm{OH}+\mathrm{H}_{2} \mathrm{O} \leftrightarrow 3 \mathrm{H}_{2} \mathrm{O}+\mathrm{CO}_{2} & \Delta \mathrm{H}=49.5 \mathrm{~kJ} / \mathrm{mol} \\
\mathrm{CH}_{3} \mathrm{OH} \leftrightarrow 2 \mathrm{H}_{2}+\mathrm{CO} & \Delta H=90.6 \mathrm{~kJ} / \mathrm{mol} \\
\mathrm{CO}+\mathrm{H}_{2} \mathrm{O} \leftrightarrow \mathrm{H}_{2}+\mathrm{CO}_{2} & \Delta H=-41.2 \mathrm{~kJ} / \mathrm{mol}
\end{array}
$$

The over-all SRM reaction is endothermic. As hydrogen-powered vehicles are nearly pollution-free, many people favor a long-term program to convert America's cars, trucks, and buses to hydrogen. Thus, it is necessary to develop technology for reforming methanol and liquid/gaseous hydrocarbons, derived from coal, as a source of hydrogen to the fuel cells with minimal production of $\mathrm{CO}$.

Catalytic SRM for hydrogen production using conventional macroscale reactors $[4,5]$ and microreactors $[1,6]$ is well known in literature. Most of the commercial catalysts available for steam reforming reactions are not environmentally viable due to their high carbon monoxide 
conversion. It was discovered by Iwasa et al. [7] that the catalytic function of Pd can be greatly modified to a highly active and selective catalyst for steam reforming by supporting $\mathrm{Pd}$ on $\mathrm{ZnO}$. The precious metal in the presence of non-noble metal support inhibits the coke formation and the oxidation of non-noble metal under atmospheric pressure. The high surface area and pore size of the catalyst support enhance dispersion and reducibility of the catalyst and is more selective towards hydrogen production. These results suggest a synergistic behavior of the bimetallic system $[8,9]$ in $\mathrm{H}_{2}$ production.

One of the best-known mesoporous support materials is MCM-41. This material displays a honeycomb-like porous structure with pore walls of approximately $1 \mathrm{~nm}$ thickness. A critical review of literature shows that synthesis of meso- and micro-porous materials with metal doped structures are good candidates for the production of hydrogen [10, 11]. However, the emission of carbon monoxide and other byproducts in these reactions cause a concern not only to catalyst poisoning but also to global warming. A major challenge of the scientific community is to develop catalyst/materials with low $\mathrm{CO}$ emission. This report covers our efforts to synthesize bimetallic nanocatalysts in MCM-41 for SRRs to produce $\mathrm{H}_{2}$.

This research covers the following fundamental topics:

1. One-pot synthesis of highly ordered MCM-41 mesoporous silica containing Pd-Ni and Pd-Co bimetallic nanoparticles.

2. Characterization of these mesoporous materials using X-ray Diffraction (XRD), Transmission Electron Microscopy (TEM), Fourier Transform Infrared Spectroscopy (FT-IR), Elemental Analysis (EDX), and Nitrogen Adsorption-Desorption studies.

3. Steam reforming of methanol (SRM) to produce hydrogen using synthesized bimetallic catalysts in MCM-41 mesoporous silica.

\subsection{Mesoporous materials}

Based on the pore size in solids, International Union of Pure and Applied Chemistry (IUPAC) classified all materials into three categories. While materials having pore size distribution larger than $500 \AA$ are macroporous, materials with pore size between $20 \AA$ and 500 $\AA$ are classified as mesoporous and materials having pore size less than $20 \AA$ are known as microporous materials. Aprile et al.[12] first reported on the formation of 'low bulk density silica'. Sylvania Electric Product Inc. filed the findings as a patent. According to their research, silica is obtained through the reaction of cetyltrimethylammonium bromide (CTAB) and 
tetraethylorthosilicates (TEOS). Although silica was not characterized completely, the researchers at the Mobil Oil Company reported a novel family of materials called M41S in 1992 $[13,14]$. The pore size constraint of microporous materials, with pore diameter smaller than 15 $\AA$, was thus overcome with the discovery of this type of material. This breakthrough assured a bright future due to their properties with a well-defined pore size between 15-100 $\AA$.

\subsubsection{Mesoporous MCM-41 molecular sieves}

The family of M41S materials can be grouped into three types (Table 1.1) and their structures are shown in Figure 1.1. Of all the M41S materials, MCM-41 is the most studied and promising material with regular arrays of uniform channels. It is possible to tailor the channel dimension in the range of 15 to $100 \AA$ or even larger with slight modification in the reaction conditions.

Table 1.1 Type of M41S mesoporous material.

\begin{tabular}{cc}
\hline Family Type & Structure \\
\hline MCM-41 & Hexagonal $(p 6 m m)$ \\
MCM-48 & Cubic $($ Ia $\overline{3} d)$ \\
MCM-50 & Lamellar \\
\hline
\end{tabular}

However, the regularity of the structure is affected with the increase in the pore size. The Brunauer-Emmet-Teller (BET) surface area is typically over $1000 \mathrm{~m}^{2} / \mathrm{g}[13,14]$. The pore volume is usually between 0.7 and $1.2 \mathrm{cc} / \mathrm{g}$.
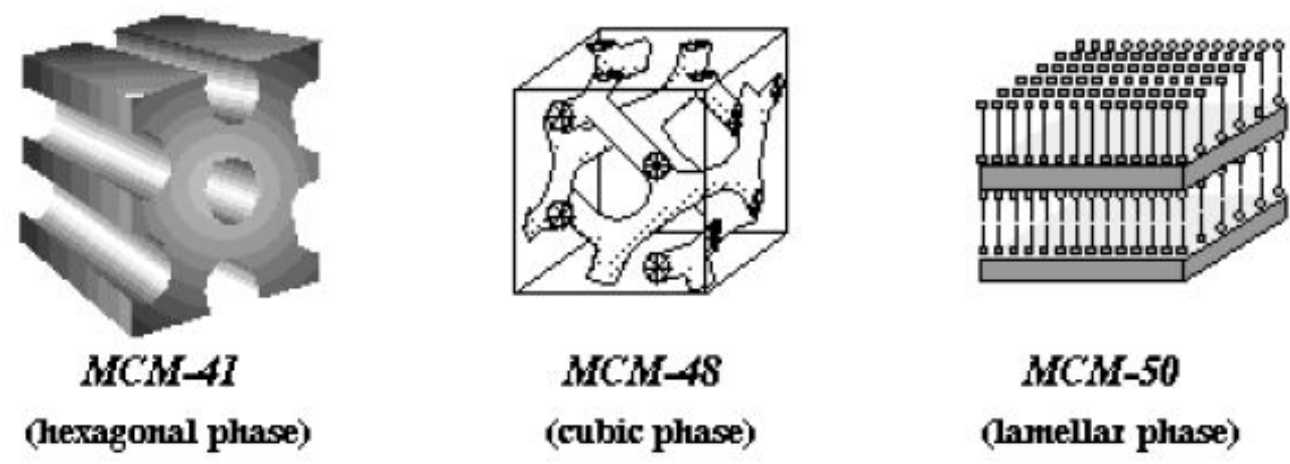

Figure 1.1 The mesoporous M41S family [14]. 
MCM-41 is composed of silica framework and it is relatively stable in acidic medium (pH 2) [15]. It possesses excellent thermal and hydrothermal stability (up to $800{ }^{\circ} \mathrm{C}$ ). However, it is not stable in basic medium ( $\mathrm{pH} 12)$. The silica framework of MCM-41 material is almost catalytically inactive. The substitution of silicone by a number of metals (Al, Ga, Fe) give rise to acidic properties [16]. The use of the pore channels of MCM-41 as a support for existing catalysts has also been investigated $[17,18]$.

\subsection{Mechanisms of formation for MCM-41}

The various routes for the synthesis of MCM-41 are based on the ion pairing between ionic silicon species and surfactants [19]. For example, $\left(\mathrm{S}^{+} \mathrm{I}^{-}\right)$direct co-condensation of anionic inorganic silicate species $\left(\mathrm{I}^{-}\right)$with a cationic surfactant $\left(\mathrm{S}^{+}\right) ;\left(\mathrm{S}^{-} \mathrm{I}^{+}\right)$direct co-condensation of cationic inorganic silicate species $\left(\mathrm{I}^{+}\right)$with an anionic surfactant $\left(\mathrm{S}^{+}\right)$; $\left(\mathrm{S}^{+} \mathrm{X}^{-} \mathrm{I}^{+}\right)$counter-ion mediated assembly where $\mathrm{X}^{-}=\mathrm{Cl}^{-}$or $\mathrm{Br}^{-}$; $\left(\mathrm{S}^{-} \mathrm{M}^{+} \mathrm{I}^{-}\right)$counter-ion mediated assembly where $\mathrm{M}^{+}=$ $\mathrm{Na}^{+}$or $\mathrm{K}^{+}$. There is also a neutral route, which is based on hydrothermal bonding between neutral silicates species and neutral surfactant $\left(\mathrm{S}^{0} \mathrm{I}^{0}\right)$. The synthesis of MCM-41 always involves a two-step liquid template mechanism. The mechanism for formation of MCM-41 is shown in Figure 1.2.

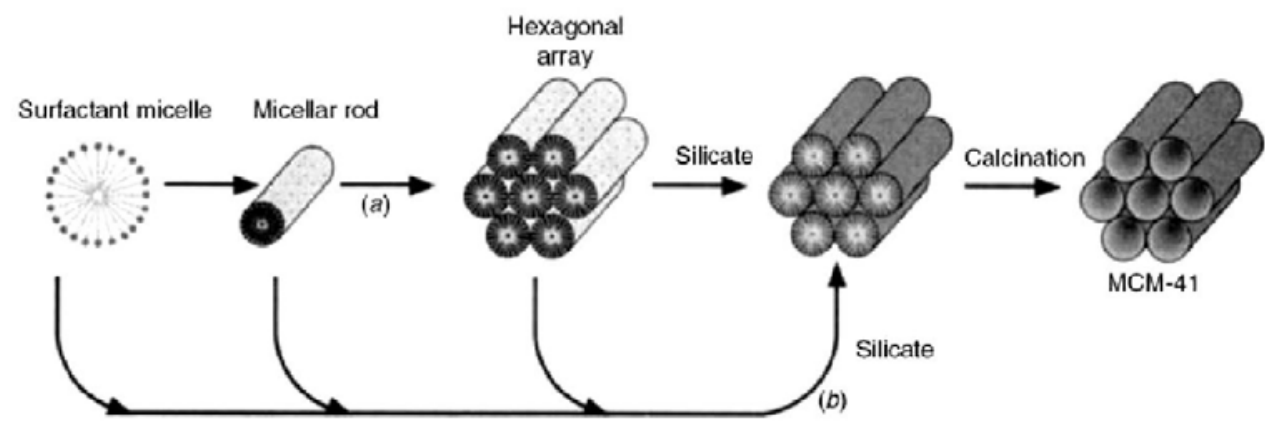

Figure 1.2 (1) Liquid crystal phase initiated and (2) silicate anion initiated MCM-41 Synthesis [14].

The first step is the co-condensation of inorganic silicon species with organic surfactant. In this early step, there are three possible mechanisms. In the first mechanism, hexagonal arrangements of micellar rods exist prior to the polymerization of the silicate species at the surface of the rods. Then, micellar rods are encapsulated into 2-3 monolayers of silica. Finally, these rods interact to form hexagonal arrangements. In the third mechanism, the hexagonal arrangement is formed through the interaction of the surfactants with the silicate species. The 
silicate species screen the charge of the surfactants, which renders possible the agglomeration of micellar rods. Nevertheless, the real mechanism depends on the reaction conditions. Finally, mesoporous MCM-41 is obtained through the removal of surfactant from the structure. This can be accomplished either by calcination or solvent-extraction of the surfactant.

\subsection{Metals in Mesoporous Materials}

The synthesis of highly dispersed metal nanoparticles in mesoporous silica had been preceded by distribution of metal ions, metal nanoparticles and metal complexes through post-synthesis or cosynthesis methods.

\subsubsection{Post-synthesis}

The post synthesis can be done in three ways such as impregnation[20,21], ion exchange [22-24] and chemical vapor deposition [25, 26]. A brief description of each synthesis procedure is included in this section. Impregnation: The incipient wetness impregnation is generally used for the preparation of supported metal catalysts [27, 28]. In this method, the solution of metal precursor is added to the template-free mesoporous material to embed or impregnate metal ions or complex into the mesochannels. However, this method rarely gives uniform distribution of metal particles. Due to lack of control, the resulting metal particles are distributed mainly within the pores of a support material [29].

Ion Exchange: To balance the negative charge on their pore walls, cationic metal ions can exchange with the counter cations exiting in pore void space of porous materials in aqueous solution. The counter ions are usually proton on silicate pore wall and present as surface silanol groups [30]. Due to its high charge/radius (e/r) value, the proton is not easy to be exchanged. Thus, the distribution of metal ions and particles generated by this method is not uniform, metal species stay both inside the pores and on the outer surface of mesoporous silica. In order to increase the capacity of ion exchange on mesoporous silicates, Chao et al. [31, 32] tried to functionalize surface silanol groups with silane (TPTAC) to form a monolayer of positive charge on intra-channel surface. In this case, the anionic counter ions $\left(\mathrm{Cl}^{-}\right)$can be exchanged almost exclusively by negatively charged metal complexes, $\mathrm{MCl}_{m}^{n-}$. Chemical vapor deposition (CVD): Due to the attachment of volatile metal complex to the surface of the support material, metal particles can be generated by CVD and subsequent decomposition of the metal complex. The pore volume of support material limits the amount of metal introduced by this procedure. This 
method may be advantageous in some cases, for instance, non-ion-exchanged porous materials are employed. A gas-phase chemical infiltration has been also developed to load Pd nanoparticles in mesoporous materials [25].

\subsubsection{Co-synthesis}

A two-step co-synthesis of metal ( $\mathrm{Au}, \mathrm{Ag}$, or Pt) - containing SBA-15 mesoporous silica was initiated and developed by Somorjai and co-workers [27, 28, 33]. Their method is based on growing the surfactant-silica composites around the preformed metal nanoparticles, which have been capped and stabilized by tri-block copolymer. First, the metal nanoparticles were prepared in a colloidal solution in the presence of a block polymer. The synthesis of polymer-silica mesophase composites was then performed by using the metal nanoparticle-polymer as template and TEOS as silica source. By this method, the metal nanoparticles in the range of 2 to $10 \mathrm{~nm}$ were incorporated into SBA-15, where the pore diameter of mesochannels was also observed to be expanded. With metal nanoparticles of size $>20 \mathrm{~nm}$, most of nanoparticles were found to be present outside of mesochannels of SBA-15.

Zhu and co-workers reported another efficient way to incorporate Au nanoparticles inside the mesochannels of mesoporous silica by a co-assembly method [34]. Their concept was to combine the complexation-mediated growth of nanoparticles and surfactant-templating synthesis of mesophase. The essence of this method is the use of bifunctional ligands that can not only complex $\mathrm{Au}$ (III) anions but also covalently bond to silicates, the species to form porous silica matrix. After reduction of Au precursor complexes and removal of templating surfactants, $\mathrm{Au}$ nanoparticles of size 2 to $5 \mathrm{~nm}$ supported on mesoporous silica have been obtained. The noble

metal nanoparticles were also found to be incorporated in mesostructured silica films and monoliths as reported by Ozin and co-workers [35]. In this case, $\mathrm{Ag}^{+}, \mathrm{AuCl}_{4}^{2-}$ and $\mathrm{PtCl}_{6}^{2-}$ ions were considered to interact with the hydrophilic head group of a non-ionic surfactant template and to be embedded within the channels of hexagonal mesostructured silica. After reduction, metal nanoparticles were found in the channels of mesoporous silica. The preparation of mesoporous silica containing $\mathrm{Au}$ nanoparticles by one-pot synthesis using the quaternary ammonium stabilized colloidal $\mathrm{Au}$ nanoparticles and TEOS as the reactants was reported by Corma and co-workers [12]. The quaternary ammonium stabilized $\mathrm{Au}$ nanoparticles were designed to have triethoxysilyl groups to co-condense with TEOS and to interact with 
cetyltrimethylammonium of the templating surfactant during the formation of the mesoporous materials. This one-pot synthesis is represented in Figure 1.3.
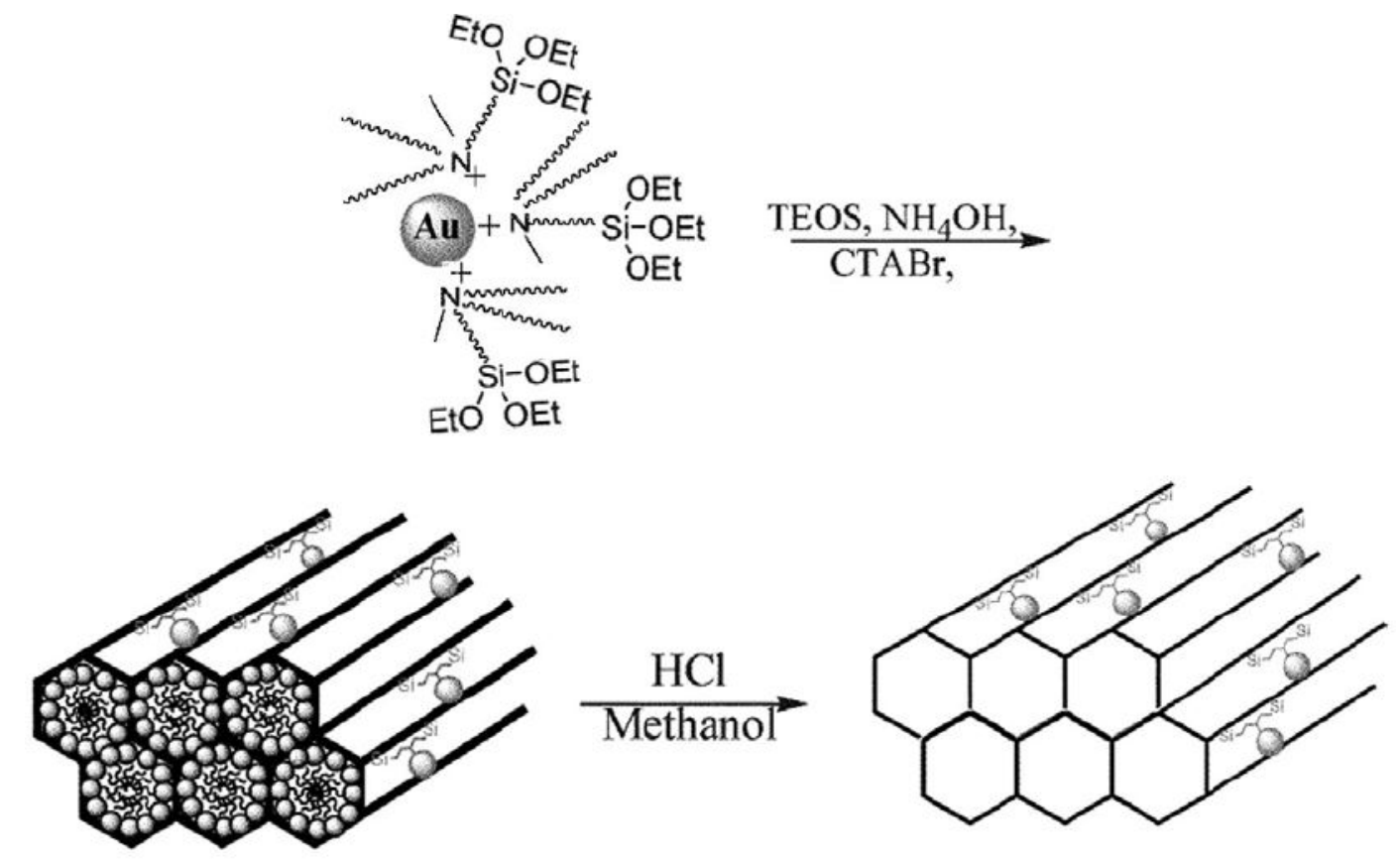

Figure 1.3 Synthesis of mpAu- $\mathrm{SiO}_{2}$ [12].

Kraeiec et al. reported an in situ synthesis of Pt-containing MCM-41 by injecting the Pt precursor into the inner core of the surfactant micelles [36]. In this method, a solution of $\mathrm{Pt}(\text { acetylacetonate })_{2}\left(\operatorname{Pt}(\mathrm{acac})_{2}\right)$ in a hydrophobic, nonpolar solvent (toluene) was used. Both $\mathrm{Pt}(\mathrm{acac})_{2}$ and toluene are immiscible in water, they can be dissolved and stabilized in the inner hydrophobic core of the surfactant micelles during the hydrothermal synthesis.

\subsection{Template removal from mesoporous silica}

In order to obtain the mesoporous silica of high surface area, the organic surfactant has to be removed from the surfactant-silica mesophase composites. The conventional method of template removal is calcination, where the samples are heated under a flow of oxygen or air. Calcination is usually efficient to burn out the organic template completely, but the high temperature treatment generally causes a loss of long range order and shrinkage of pore structure [37]. 


\section{EXPERIMENTAL}

\subsection{Chemicals}

All materials used were analytical grade and used without further purification. Deionized distilled water was used throughout the experiment, unless indicated. Cetyltrimethyleammonium Bromide (98\%), Tetramethylorthosilicate $(98 \%)$ and $\mathrm{CoCl}_{2} \cdot 6 \mathrm{H}_{2} \mathrm{O}$ were purchased from SigmaAldrich. The precursors for palladium and nickel, $\mathrm{Pd}\left(\mathrm{NO}_{3}\right)_{2}$ and $\mathrm{Ni}\left(\mathrm{NO}_{3}\right)_{2} \cdot 6 \mathrm{H}_{2} \mathrm{O}$, respectively, were obtained from Alfa-Aesar. Ammonium hydroxide, ethanol and acetone were obtained from Fisher Scientific.

\subsection{Synthesis}

\subsubsection{MCM-41}

MCM-41 was synthesized following the procedure reported in literature [38, 39] with a slight modification in the reaction condition and the molar ratio 0.136 CTAB: 1 TMOS: $5.3 \mathrm{NH}_{4} \mathrm{OH}$ : $172 \mathrm{H}_{2} \mathrm{O}$. In this synthesis work, $2.5 \mathrm{gm}$ of cationic surfactant CTAB was dissolved in $120 \mathrm{ml}$ water at $30{ }^{\circ} \mathrm{C}$ followed by addition of $10 \mathrm{ml}$ of ammonium hydroxide. The mixture was stirred well and $10 \mathrm{ml}$ of tetra-methylorthosilicate (TMOS) was slowly added to the surfactant solution. The solution was stirred for 2 hours at room temperature to yield a white precipitate. It was then heated at $80{ }^{\circ} \mathrm{C}$ for 24 hours followed by cooling at room temperature. The precipitate was filtered and washed with distilled $\mathrm{H}_{2} \mathrm{O}$ until the filtrate had a $\mathrm{pH}$ of 7 and finally washed with acetone. The filtered material was dried in an oven at $100{ }^{\circ} \mathrm{C}$ for 16 hours to give the as synthesized sample (MCM-41 as). It was then calcined at $560{ }^{\circ} \mathrm{C}$ to remove $\mathrm{CTAB}$ to form the calcined sample (MCM-41c).

\subsubsection{One-pot synthesis of mono- metallic (Pd, Ni \& Co) and bi-metallic (Pd-Ni \& Pd-Co) MCM-41}

The bi-metallic nanocatalyst supported on MCM-41 mesoporous silica were prepared following the optimized one-pot synthesis procedure [40]. Metal salts of palladium (II) nitrate $\left[\mathrm{Pd}\left(\mathrm{NO}_{3}\right)_{2}\right]$, nickel(II) nitrate hexahydrate $\left[\mathrm{Ni}\left(\mathrm{NO}_{3}\right)_{2} \cdot 6 \mathrm{H}_{2} \mathrm{O}\right]$ and cobalt chloride hexahydrate $\left[\mathrm{CoCl}_{2} \cdot 6 \mathrm{H}_{2} \mathrm{O}\right]$ were used as the metal precursors and tetramethylorthosilicate (TMOS) as the source of silica. The CTAB and ammonia were used as the structure-directing agent and a precipitating agent, respectively. The amount of TMOS, CTAB, ammonia and water were fixed in all the samples. 
Different amounts of metal salts were used to vary the $\mathrm{Pd} / \mathrm{Ni}$ ratios in the samples. Reference samples containing palladium and nickel alone were also synthesized. The molar ratio composition of the different Pd-Ni and Pd-Co catalysts are shown in Table 2.1. The catalysts were designated as (metal-metal-batch no) for example Pd-Ni-B1 indicate batch 1 of Pd-Ni catalyst or Pd-Co-B1 indicates the batch 1 of Pd-Co catalyst.

The procedure to synthesize all the samples is same except for the amount of metal salts in different batches. In a typical synthesis, $0.8 \mathrm{gm}$ of CTAB was dissolved in $40 \mathrm{ml}$ water keeping the temperature constant $\left(40^{\circ} \mathrm{C}\right)$. The $\mathrm{pH}$ of the resulting solution was 7. Certain amount of first metal salt was dissolved in $20 \mathrm{ml}$ ethanol in a separate beaker. After the first metal salt was completely dissolved in ethanol, second metal salt was added with continuous stirring. The $\mathrm{pH}$ of the salt solution was close to 4 . The bi-metallic solution was added very slowly to the CTAB solution while stirring vigorously for 20 minutes. Then, $2.59 \mathrm{ml}$ of TMOS was added to the mixture and stirred well to hydrolyze the silica precursor. After stirring for 30 minutes, 3.35 $\mathrm{ml}$ of ammonia was added to the solution and the resulting solution was stirred for 3 hours. The resulting material was kept in an oven at $65{ }^{\circ} \mathrm{C}$ for 14 hours. The solid product was filtered, washed with water until the filtrate $\mathrm{pH}$ was 7 . The material was finally washed with acetone and ethanol to remove any physisorbed species present in the sample. The filtered material was dried at $100{ }^{\circ} \mathrm{C}$ for 8 hours to give the as synthesized sample, which was calcined at $560{ }^{\circ} \mathrm{C}$ for 10 to 20 hours. 
Table 2.1 The molar ratio of different metals in the Pd-Co and Pd-Ni-MCM-41 samples

\begin{tabular}{c|cc|cc}
\hline & \multicolumn{2}{|c|}{ Pd-Ni Catalyst Composition } & \multicolumn{2}{c}{ Pd-Co Catalyst Composition } \\
\hline Batch & Ni & Pd & Co & Pd \\
\hline B1 & 3.62 & 0.59 & 4.57 & 0.55 \\
\hline B2 & 5.32 & 0.81 & 6.83 & 0.81 \\
\hline B3 & 5.15 & 4.01 & - & 1.13 \\
\hline B4 & 5.05 & 5.75 & 9.80 & 3.65 \\
\hline B5 & 24.83 & 2.46 & 4.51 & - \\
\hline B6 & - & - & 4.44 & 8.98 \\
\hline Pd-MCM-41 & 5.36 & - & - & - \\
\hline Co-MCM-41 & - & 8.26 & 6.64 & \\
\hline
\end{tabular}

\subsection{Characterization}

\subsubsection{X-ray diffraction (XRD) measurement}

To identify the crystalline phase and to determine the phase purity of the as synthesized and calcined M/MCM-41 (M = Pd, Ni) were carried out by X-ray diffraction (XRD). Small and wide-angle powder XRD patterns were measured using Bruker AXS D8 Discover X-ray diffractometer system with a monochromated $\mathrm{CuK} \alpha$ radiation source $(\lambda=1.54160 \mathrm{~A})$ operated at $40 \mathrm{kV}$ and $200 \mathrm{~mA}$. The samples were scanned from 0.5 to $7(2 \theta)$ in steps of 0.01426 with a count of 0.3 second at each point. To protect the detector from the high energy beams, slits were used in this work.

\subsubsection{Nitrogen adsorption/desorption measurement}

The pore diameter, pore volume, and surface area of the samples were derived from nitrogen adsorption isotherms at $77 \mathrm{~K}$. Nitrogen adsorption/desorption measurements were performed 
using a NOVA Quantachrome 2200e Surface Area and Pore Size Analyzer at liquid nitrogen temperature of $77 \mathrm{~K}$. Before each experiment, samples were de-gassed at $350{ }^{\circ} \mathrm{C}$ for 4 hours under vacuum.

\subsubsection{Transmission electron microscopy analysis (TEM)}

Electron microscopy was performed with a Cold Field Emission Hitachi HF 2000 transmission electron microscope operated at $200 \mathrm{kV}$ accelerating voltage. For the measurements, a small pinch of fine powder (20 to $30 \mathrm{mg}$ ) was ultrasonically dispersed in methanol. This process separated the agglomerated particles. A drop of the resulting, highly diluted suspension was applied on a copper grid and the solvent was allowed to evaporate.

\subsubsection{Fourier transform infrared spectroscopy (FT-IR)}

The FTIR spectra were recorded using Shimadzu IR Prestige - 21 Fourier transform infrared (FTIR) 8300 spectrometer. The method used is known as $\mathrm{KBr}$ technique. The sample was first finely ground. Powdered sample was diluted with spectral grade potassium bromide with 1: 200 ratio and ground into a homogeneous powder. It was then loaded into a $13 \mathrm{~mm}$ manual die and pressed to form a self-supporting pellet. The pellet was mounted on the sample holder and the spectrum was recorded in the range 4000 to $400 \mathrm{~cm}^{-1}$ at $4 \mathrm{~cm}^{-1}$ resolution at ambient temperature.

\subsubsection{Thermo gravimetric analysis (TGA)}

Thermal gravimetric analysis is a simple analytical technique that measures the weight loss (or weight gain) of a material as a function of temperature under a gas flow. As a sample is heated, it can lose weight from a simple process such as drying, or from chemical reactions, those liberate gases. It is a useful technique to monitor the removal of organic template from as synthesized mesoporous silica materials. The removal of surfactant CTAB from all the as synthesized singlemetallic and bi-metallic MCM-41 materials were investigated by using a Seiko TGA/DTA 300 instrument. The samples were heated from 25 to $500{ }^{\circ} \mathrm{C}$ with a heating rate of $1{ }^{\circ} \mathrm{C} \mathrm{min}{ }^{-1}$ under air flow of $100 \mathrm{ml} / \mathrm{min}$. The temperature were held at $100^{\circ} \mathrm{C}$ for 2 hours under $\mathrm{H}_{2} / \mathrm{Ar}=1 / 9$ flow, and then increased from $100{ }^{\circ} \mathrm{C}$ up to $500{ }^{\circ} \mathrm{C}$ in air, $\mathrm{He}$, or $\mathrm{H}_{2} / \mathrm{Ar}$ flow with a heating rate of $2{ }^{\circ} \mathrm{C}$ $\min ^{-1}$. 


\subsection{Steam Reforming of Methanol}

\subsubsection{Description of the experimental setup}

A detailed process flow diagram (PFD) of the experimental facility used in this study is shown in Figure 2.1. In the methanol reforming system, water-methanol premix composed of 3:1 molar ratio, was stored in a reservoir. A micro-pump sends the premix to an electrically powered tubular furnace (vaporizer) through a three-way valve. Once the premix is vaporized, it moves to the reactor through the piping that is heated electrically to prevent condensation. After the steam reforming reaction in the catalyst bed, the products and unused reactants leave the reactor and enter the condensation unit. The condensation unit composed of a custom built stainless-steel condenser which is immersed in an ice-bath. The dry product from SRM reaction goes to the gas chromatograph and to the vent. At the condensing unit, all the unreacted water and methanol were condensed and analyzed to determine the conversion of methanol.

The gas analyses at the reactor outlet are carried out by a gas chromatograph (Hewlett Packard 6890) which is connected on- line to the reactor outlet stream. The gas chromatograph is equipped with a thermal conductivity detector (TCD) and a Restek shincarbon micropacked column, capable of separating the reforming products $\left(\mathrm{CO}, \mathrm{CO}_{2}, \mathrm{CH}_{4}, \mathrm{H}_{2}\right)$ in a single injection. The temperature of the ice-bath is always maintained close to $0{ }^{\circ} \mathrm{C}$ to ensure that all unreacted species were collected in the condensate trap. A helium cylinder is also connected to the system before the vaporizer through the three-way valve. The whole system was purged thoroughly with helium before each experiment to remove all the air and other gases from the system. A hydrogen cylinder $\left(4 \% \mathrm{H}_{2}\right.$ and balance $\left.\mathrm{He}\right)$ is connected to the reactor to activate the catalyst in situ. A flow controller controls the flow of the $4 \%$ hydrogen gas during the activation process.

\subsubsection{Design of the steam reforming reactor}

The drawing of the reactor used in this study is shown in Figure 2.2. The reactor was constructed from a 3.6 inch stainless-steel pipe (nominal 3/4 inch Dia., schedule 40) welded to a flange at both ends. The top and bottom portion of the reactor are 1/4 inch tube. The reactor was heated electrically from outside using a K-type omega heating tape. A K-type thermocouple along with an omega temperature controller was used to control the temperature of the reactor. 


\subsubsection{Description of the steam reforming of methanol experiment}

All catalysts were reduced in $4 \%$ hydrogen gas environment at $550{ }^{\circ} \mathrm{C}$ for 8 to 10 hours for activation. The reduced catalysts were placed in the reactor. The length of the catalyst zone in the reactor was about 3 inches. The reactor is a fixed bed type reactor and a very low amount of catalyst $(300 \mathrm{mg}$ ) was loaded. Both sides of the reactor were packed with glass wool. The catalysts were again reduced in situ by flowing $4 \%$ hydrogen for 4 hours at $400{ }^{\circ} \mathrm{C}$. Before each experiment, the whole system was purged thoroughly with helium to remove air and any other gases present in the system. The liquid feed was adjusted to a water/methanol molar ratio of 3. The premix feed solutions were injected to the system by a micropump at flow rates $0.1,0.2$ and $0.3 \mathrm{ml} / \mathrm{min}$. The temperature of the reactor was varied from 250 to $300{ }^{\circ} \mathrm{C}$. The operating conditions used in the steam reforming reactions are summarized in Table 2.2.

Table 2.2 Operating conditions used in steam reforming of methanol.

\begin{tabular}{ll}
\hline Operating Parameter & Range \\
\hline Temperature $\left({ }^{\circ} \mathbf{C}\right)$ & 250 to 350 \\
Feed flow rate $(\mathbf{m l} / \mathbf{m i n})$ & $0.1,0.2,0.3$ \\
Steam to methanol molar ratio & $3 / 1$ \\
Catalyst Loading & \\
Amount of Catalyst $(\mathbf{m l})$ & 1.7 \\
Sand $(\mathbf{m l})$ & 1.7 \\
\hline
\end{tabular}

Using the composition of the reactor effluent stream, methanol conversion, selectivity of different products and hydrogen yield were evaluated from the definitions of equations $3.1-3.3$.

Methanol conversion:

$$
\mathrm{X}_{\mathrm{CH} 3 \mathrm{OH}}=\frac{\text { Moles of Methanol converted }}{\text { Moles of Methanol fed to the reactor }}
$$

Yield of hydrogen:

$$
\mathrm{Y}_{\mathrm{H}_{2}}=\frac{\text { Moles of hydrogen produced }}{\text { Moles of Methanol fed to the reactor }}
$$

Selectivity of product A:

$$
\mathrm{S}_{\mathrm{A}}=\frac{\text { Moles of product } \mathrm{A} \text { formed }}{\text { Total number of moles of the product }}
$$




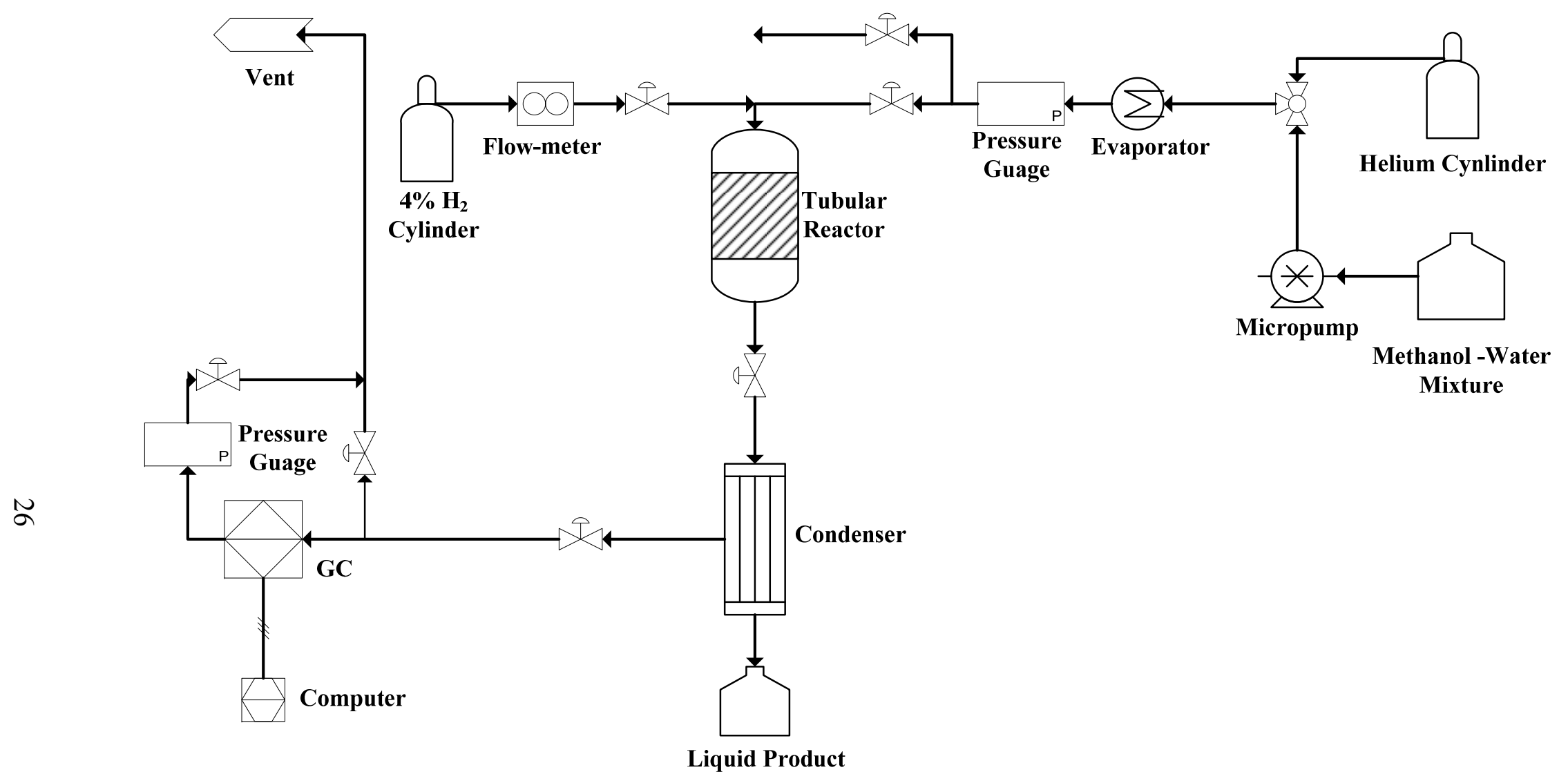

Figure 2.1 Schematic of the steam reforming experimental setup 


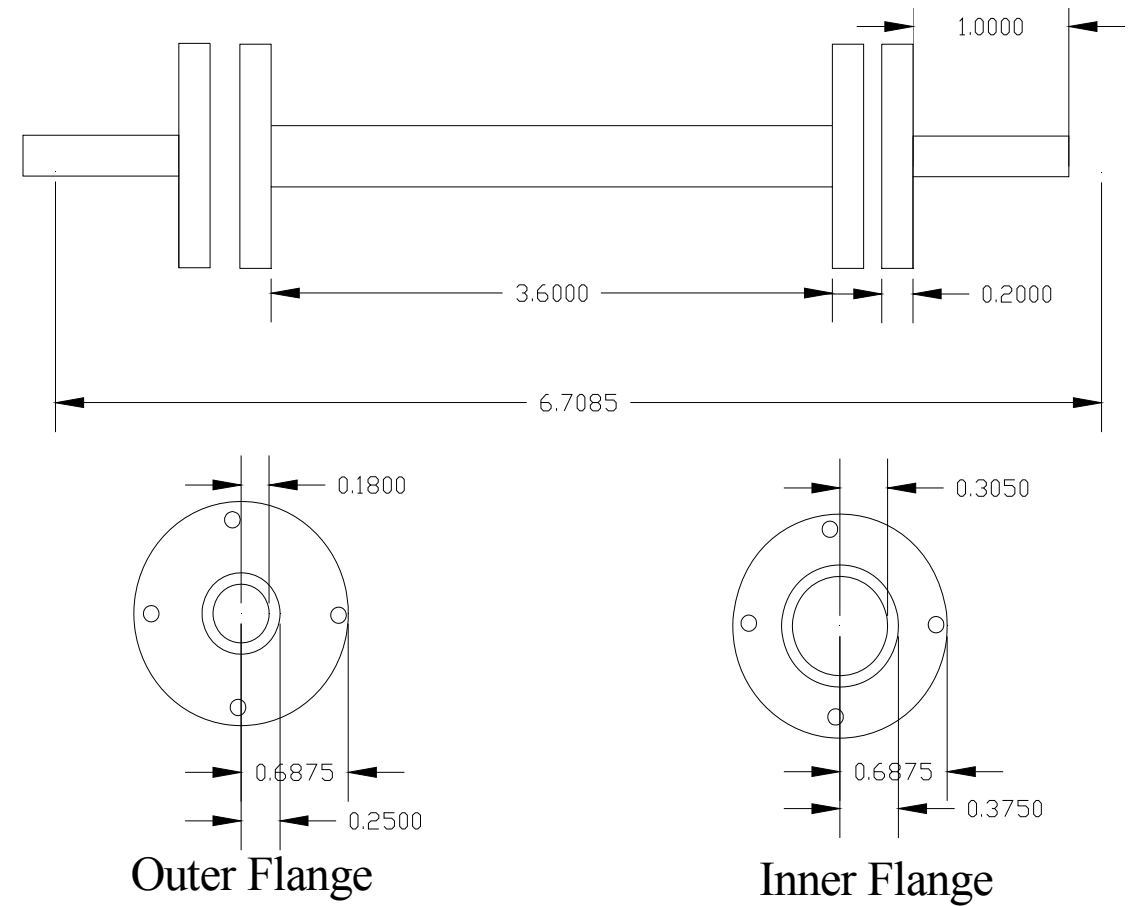

Figure 2.2 Design of the steam reforming reactor.

\section{RESULT AND DISCUSSION}

\subsection{Catalyst Characterization}

\subsubsection{Small angle XRD measurements}

The ordered mesoporous structure of the material was confirmed by small-angle X-ray diffraction studies. The small-angle XRD patterns of MCM-41, Pd/MCM-41, and Ni/MCM-41 are shown in Figure 3.1. The relatively well-defined patterns related to MCM-41 materials are similar to that described by [41]. Three reflections (100), (110) and (200) of hexagonal P6mm space group are well resolved and indexed. The XRD pattern of calcined MCM-41 shows a strong peak at $2 \theta=2.2^{\circ}$ and weak peaks at $2 \theta=3.9^{\circ}$ and $4.5^{\circ}$, The $d$-spacing was calculated using equation 4.1

$$
d=\frac{\lambda}{2 \sin \theta} \text { and } \lambda=1.5416
$$


The ratio of $\mathrm{d}_{100}: \mathrm{d}_{110}: \mathrm{d}_{200}$ is in good agreement to the theoretical value of $P 6 \mathrm{~mm}$, an indication of the sample is in a high ordered hexagonal mesoporous structure. The Figure 3.2 and Figure 3.3 show the effect of calcination on Ni/MCM-41 and Pd-Ni/MCM-41 (B5) materials. The diffraction peaks moved to a higher angle after calcination. The shift to higher values of $2 \theta$ and increase in peak intensity upon calcination corresponds to strengthening of the lattice caused by completion of silicate condensation and better crystalline material [42]. The XRD patterns of other samples before and after calcinations also showed similar results.

The small-angle XRD patterns of bi-metallic Pd-Ni/MCM-41 and Pd-Co/MCM-41 with different ratio of metal loadings are shown in Figure 3.4 and Figure 3.5 respectively. The $\mathrm{d}_{210}$ peaks were too weak to be recognized in the bi-metallic species and it might be due to the incorporation of heteroatoms into the framework of MCM-41, and therefore, caused the decrease of the ordered structure.

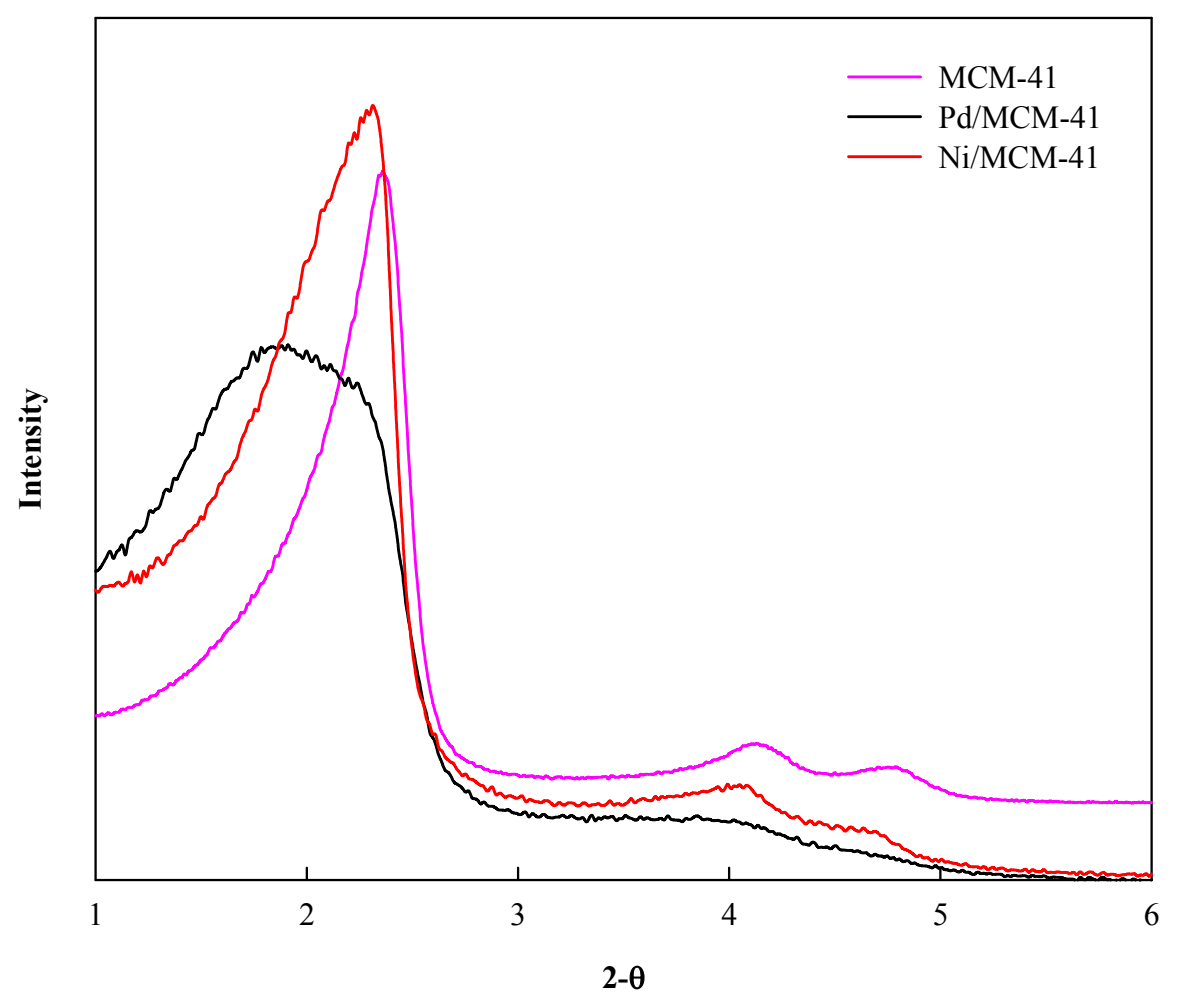

Figure 3.1 Small-angle XRD patterns of MCM-41 and single-metallic Pd/MCM-41 and $\mathrm{Ni} / \mathrm{MCM} 41$. 


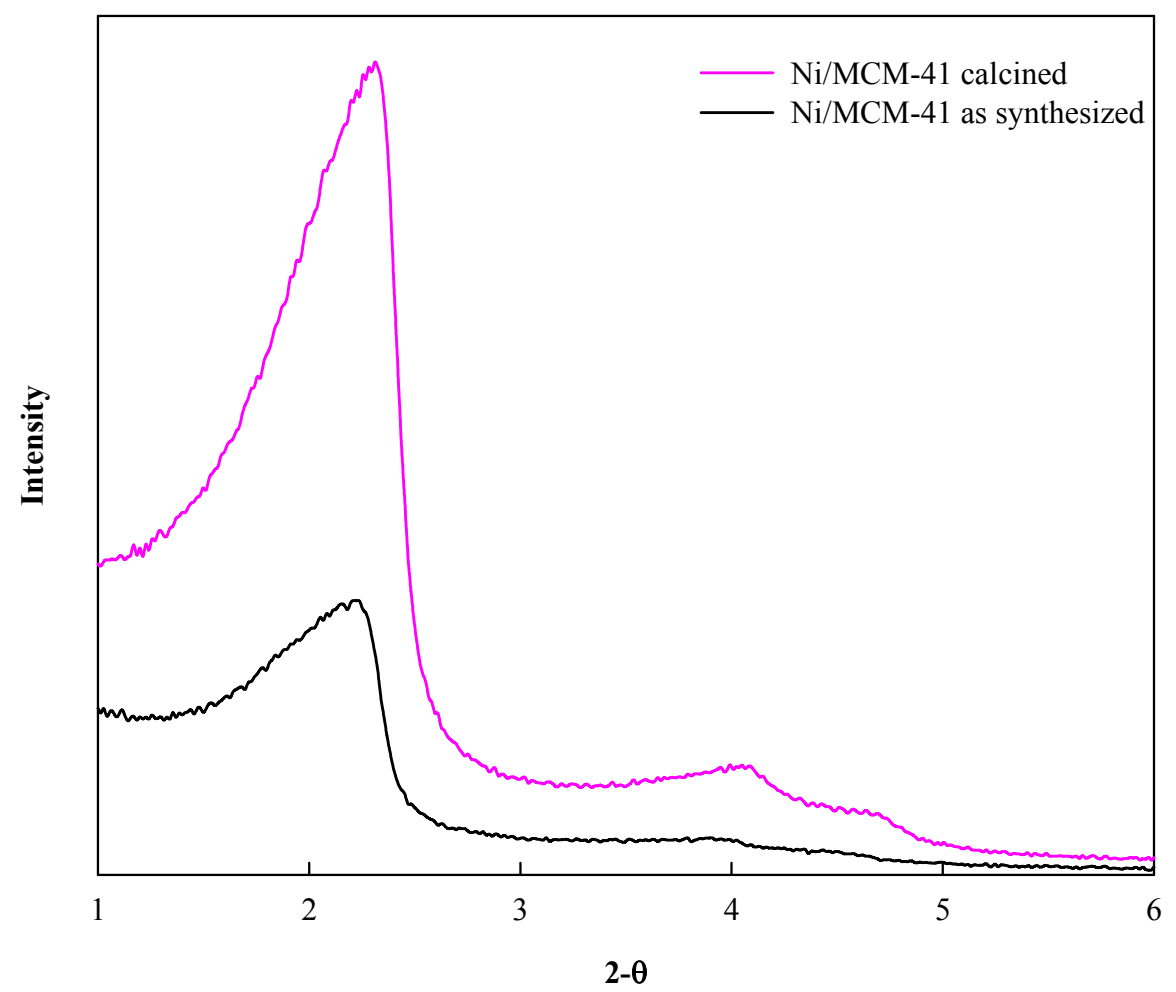

Figure 3.2 Small-angle XRD pattern of Ni/MCM-41 before and after calcination.

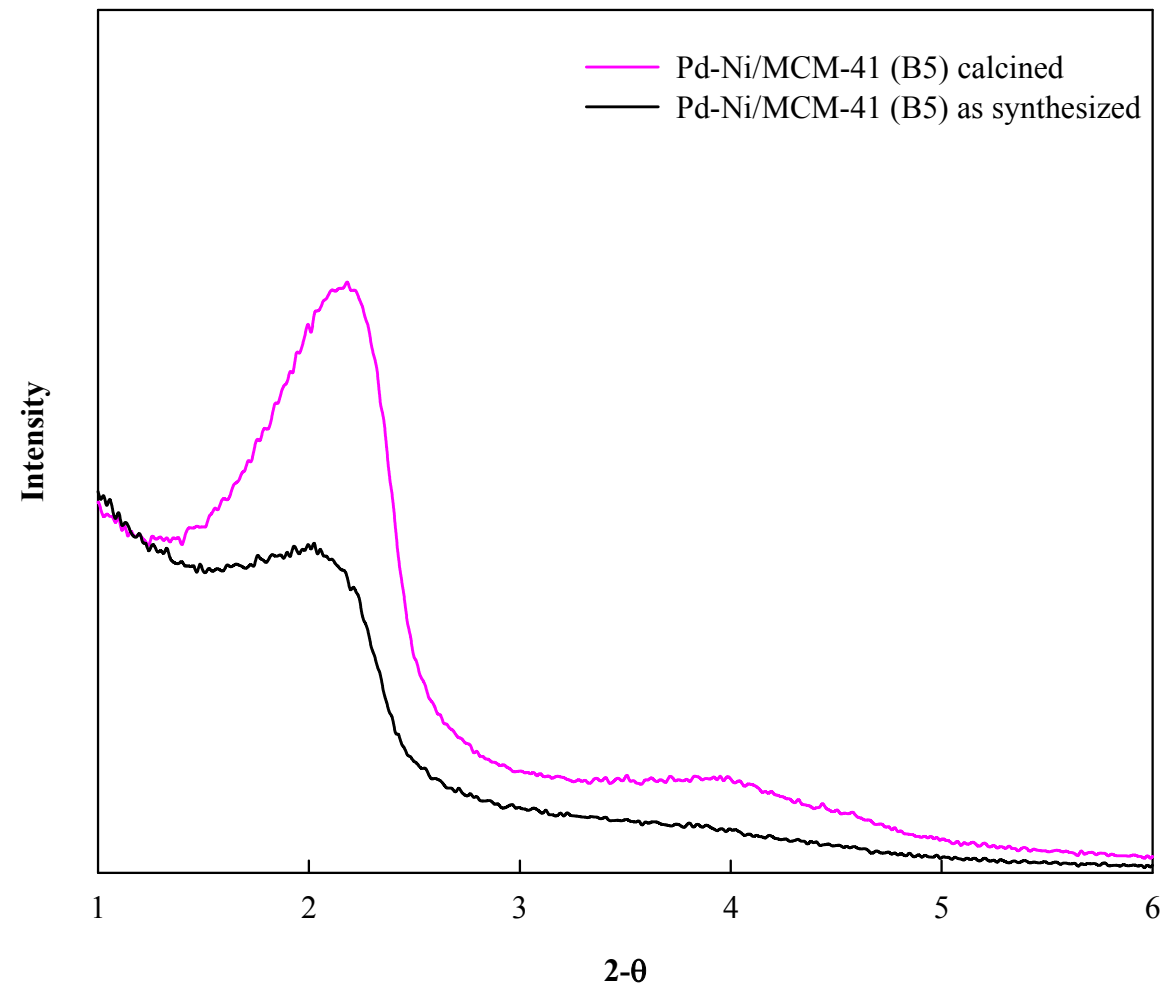

Figure 3.3 Small-angle patterns of Pd-Ni/MCM-41 (B5) before and after calcination. 


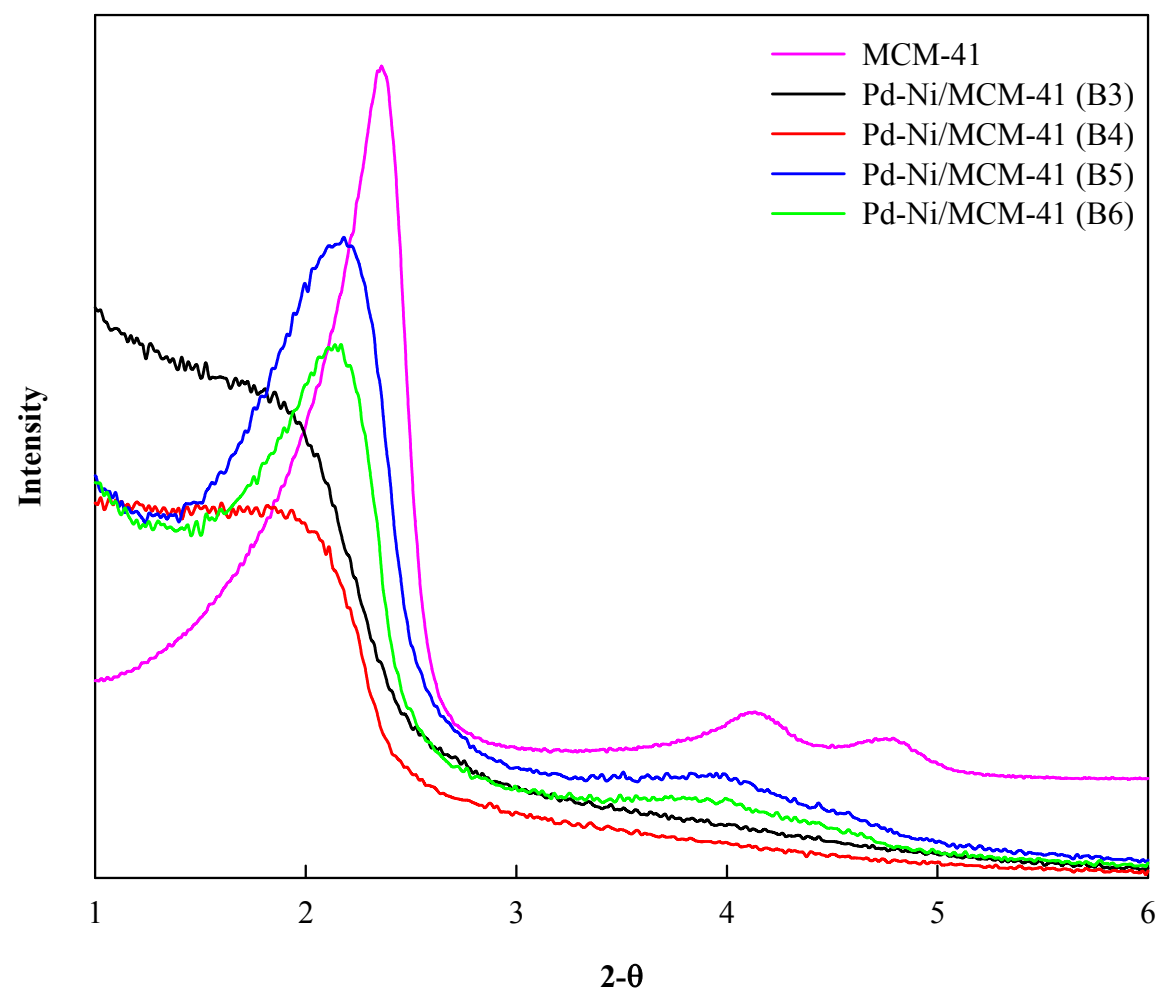

Figure 3.4 Small-angle XRD patterns of different Pd-Ni bi-metallic samples.

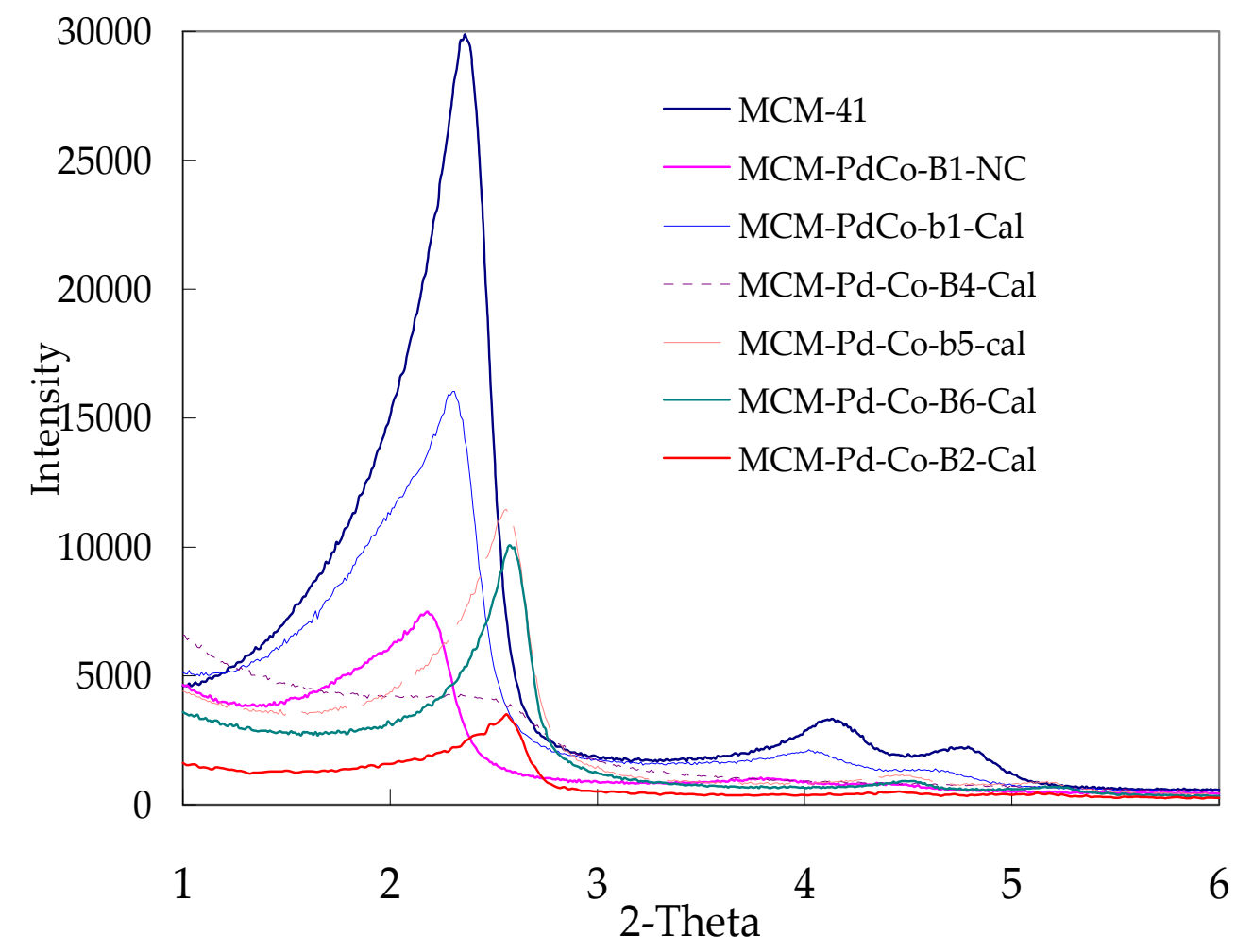

Figure 3.5 Small-angle XRD patterns of different Pd-Co-MCM-41samples. 
The values of $\mathrm{a}_{0}$ (length of the hexagonal unit cell) are calculated by using the formula:

$$
a_{0}=\frac{2 d_{100}}{\sqrt{3}}
$$

and according to the relationship:

$$
\frac{l}{d_{h k l}^{2}}=\frac{4\left(h^{2}+h k+k^{2}\right)}{3 a}+\frac{l^{2}}{c^{2}}
$$

The calculated values of $\mathrm{a}_{0}$ are listed in Table 3.1. The unit cell parameter increases with the Pd and Ni loading, suggesting that the incorporation of metals seems to expand the space of micelles and to enlarge the diameter of mesochannels. The shrinkages of $\mathrm{d}_{100}$ are $12.97 \%, 3.7 \%, 7.19 \%$ and $5.33 \%$ in $\mathrm{Pd} / \mathrm{MCM}-41, \mathrm{Ni} / \mathrm{MCM}-41, \mathrm{Pd}-\mathrm{Ni} / \mathrm{MCM}-41$ (B5) and $\mathrm{Pd}-\mathrm{Ni} / \mathrm{MCM}-41$ (B6) materials were observed respectively after calcination. It indicates that the incorporation of metal precursor in the templating micelles might have disturbed the packing of surfactants in MCM-41 mesophase and the stability of mesostructure during calcination. The $\mathrm{d}_{100}$ values of parent MCM41 and PdCo-MCM-41 samples are $37.53 \AA$ and $34.03 \AA$, respectively. The decrease in the $d$ values and unit cell parameters on incorporation of PdCo is probably due to the presence of bimetallic nanostructures on the pore walls or frame work of silica network of MCM-41. Furthermore, the decreasing intensities and broadening of the peaks are indicative of the loss of the long-range order due to interaction of PdCo with silica. 
Table 3.1 The d-spacing, cell dimension $\left(\mathrm{a}_{0}\right)$ and shrinkage of $\mathrm{d}$-spacing before and after calcinations of all the samples.

\begin{tabular}{lccc}
\hline \multicolumn{1}{c}{ Sample } & d-spacing, $\AA$ & $\mathbf{a}_{0}, \AA$ & Shrinkage (\%) \\
\hline MCM-41 & 40.15 & 46.36 & - \\
Pd/MCM-41 as synthesized & 54.31 & 62.71 & - \\
Pd/MCM-41 calcined & 47.26 & 54.57 & 12.97 \\
Ni/MCM-41 as synthesized & 39.69 & 45.83 & - \\
Ni/MCM-41 calcined & 38.22 & 44.13 & 3.7 \\
Pd-Ni/MCM-41 (B3) calcined & 47.62 & 54.99 & - \\
Pd-Ni/MCM-41 (B4) calcined & 48.37 & 55.85 & - \\
Pd-Ni/MCM-41 (B5) as synthesized & 43.60 & 50.35 & - \\
Pd-Ni/MCM-41 (B5) calcined & 40.47 & 46.73 & 7.19 \\
Pd-Ni/MCM-41 (B6) as synthesized & 43.60 & 50.35 & - \\
Pd-Ni/MCM-41 (B6) calcined & 41.28 & 47.66 & 5.33 \\
\hline
\end{tabular}

\subsection{2 $\mathrm{N}_{2}$ Adsorption-Desorption}

The isotherms of Pd-Ni-MCM-41, Pd-MCM-41 and Ni-MCM-41 samples are shown in Figure 3.6. The adsorption-desorption isotherms were of type IV, typical of mesoporous solid materials [43]. From the isotherms, three well-defined stages were observed: 1) At a low relative pressure, a slow rate of increase in nitrogen uptake, corresponds to monolayer-multilayer adsorption on the pore walls. 2) A sharp step at intermediate relative pressure is indicative of capillary condensation within mesopores. 3) A plateau with a slight inclination at high relative pressures, associated with multilayer adsorption on the external surface of the crystals [44]. A fourth stage, characterized by a sharp rise in $\mathrm{N}_{2}$ uptake filling all other available pores as the pressure reaches saturation $\left(\mathrm{P} / \mathrm{P}_{\mathrm{o}}=1.0\right)$, may be identified in some of the isotherms. 


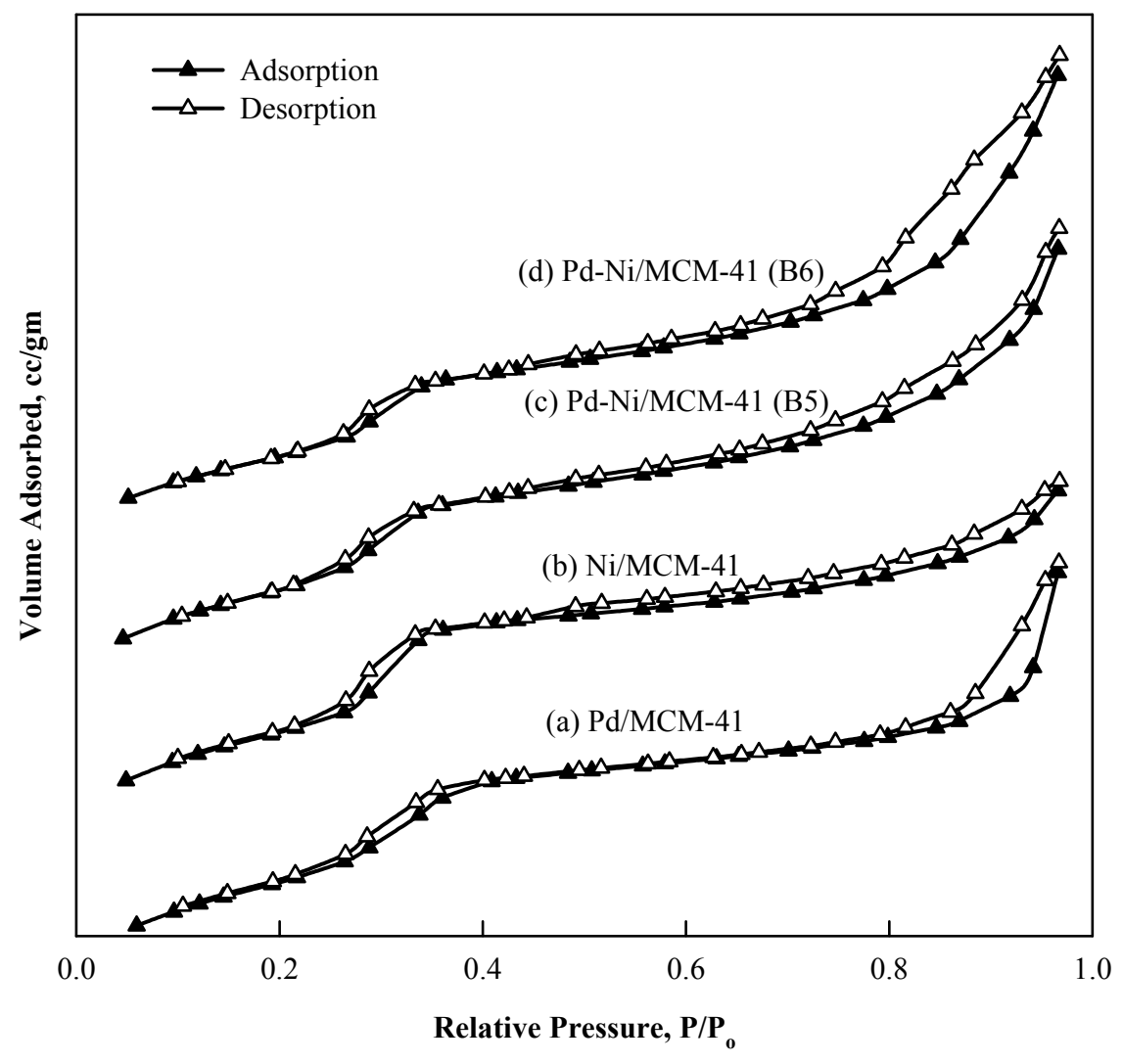

Figure 3.6 Nitrogen adsorption-desorption isotherms of calcined (a) Pd/MCM-41, (b) Ni/MCM41, (c) Pd-Ni/MCM-41 (B5) and (d) Pd-Ni/MCM-41 (B6) samples.

The third stage of the isotherm shifts slightly toward higher relative pressure with the incorporation of palladium and nickel ions. The hysteresis loop is broadened with an increase in the metal content, suggesting some disorder in the pore system arising from metal incorporation. Incorporation of metals in MCM-41 material has a significant effect on structural parameters. The values of surface area decrease with increasing metal content. The pore volume, pore diameter, and wall thickness in bi-metallic and single-metallic MCM-41 materials increase upon increasing the metal loading; the values are listed in Table 3.2.

In crystalline zeolites, the pore size increases upon increasing the metal ion content because of their longer bond length with oxygen than with Si-O. In the case of MCM-41, both the bond length and angle may change because of their amorphous nature; therefore, there is no general rule. It is generally observed that the pore size of MCM-41 decreases after metal incorporation. However, there is no clear explanation for this observation. As shown in Table 3.2, the pore size increased after both palladium and nickel ions were incorporated. This result strongly suggests that metal ions are incorporated into the silica framework according to the 
above hypothesis. This finding can be confirmed indirectly by the ease of metal reduction; and has been reported previously [45]. From the Figure 3.7, one can see that very narrow pore size distributions are obtained for all the samples containing palladium and nickel. The narrow pore size is indicative of the uniform mesoporosity. The pore distribution becomes broader, indicating that the ordering of sample decreases as the content of the heteroatom increase.

Table 3.2 Physicochemical characterization of as synthesized and calcined materials of different samples

\begin{tabular}{|c|c|c|c|c|}
\hline Sample Name & $\begin{array}{c}\text { Surface area } \\
\left(\mathrm{m}^{2} / \mathrm{g}\right)\end{array}$ & $\begin{array}{c}\text { Pore size }^{\mathrm{a}} \\
\text { (Á) }\end{array}$ & $\begin{array}{c}\text { Pore volume }^{\mathrm{a}} \\
\left(\mathrm{cm}^{3} / \mathrm{g}\right)\end{array}$ & $\begin{array}{c}\text { Pore wall } \\
\text { thickness }{ }^{\mathbf{b}}(\mathbf{A})\end{array}$ \\
\hline MCM-41 & 974 & 28 & 0.638 & 18.36 \\
\hline \multicolumn{5}{|l|}{ Pd-MCM-41 as } \\
\hline $\begin{array}{l}\text { Pd-MCM-41 } \\
\text { calcined }\end{array}$ & 857.81 & 30.6 & 0.709 & 23.97 \\
\hline \multicolumn{5}{|l|}{ Ni-MCM-41 as } \\
\hline $\begin{array}{l}\text { Ni-MCM-41 } \\
\text { calcined }\end{array}$ & 876.53 & 28.22 & 0.732 & 15.91 \\
\hline \multicolumn{5}{|l|}{ Pd-Ni-B6 as } \\
\hline Pd-Ni-B6 calcined & 778.74 & 29.41 & 0.885 & 18.25 \\
\hline Pd-Ni-B5 as & 640.81 & 28.22 & 0.568 & 22.13 \\
\hline Pd-Ni-B5 calcined & 861.01 & 28.22 & 0.837 & 18.51 \\
\hline Pd-Ni-B4 calcined & 546.05 & 29.41 & 0.541 & 26.44 \\
\hline Pd-Co-B1 & 828 & 21.8 & 0.552 & 18.15 \\
\hline Pd-Co-B2 & 845 & 21.7 & 0.434 & 18.02 \\
\hline Pd-Co-B6 & 775 & 21.6 & 0.571 & 18.1 \\
\hline
\end{tabular}

\footnotetext{
${ }^{a}$ Values obtained from $\mathrm{N}_{2}$ adsorption results.

${ }^{\mathrm{b}}$ Wall thickness $=$ unit cell parameter - pore size.
} 
In Figure 3.8 and Figure 3.9, the isotherm and pore size distribution of as synthesized sample of Pd-Ni/MCM-41 B5 to those of calcined sample of Pd-Ni/MCM-41B5 are plotted. After calcination, the pore distribution becomes narrower which implies that the sample becomes more ordered after calcination.

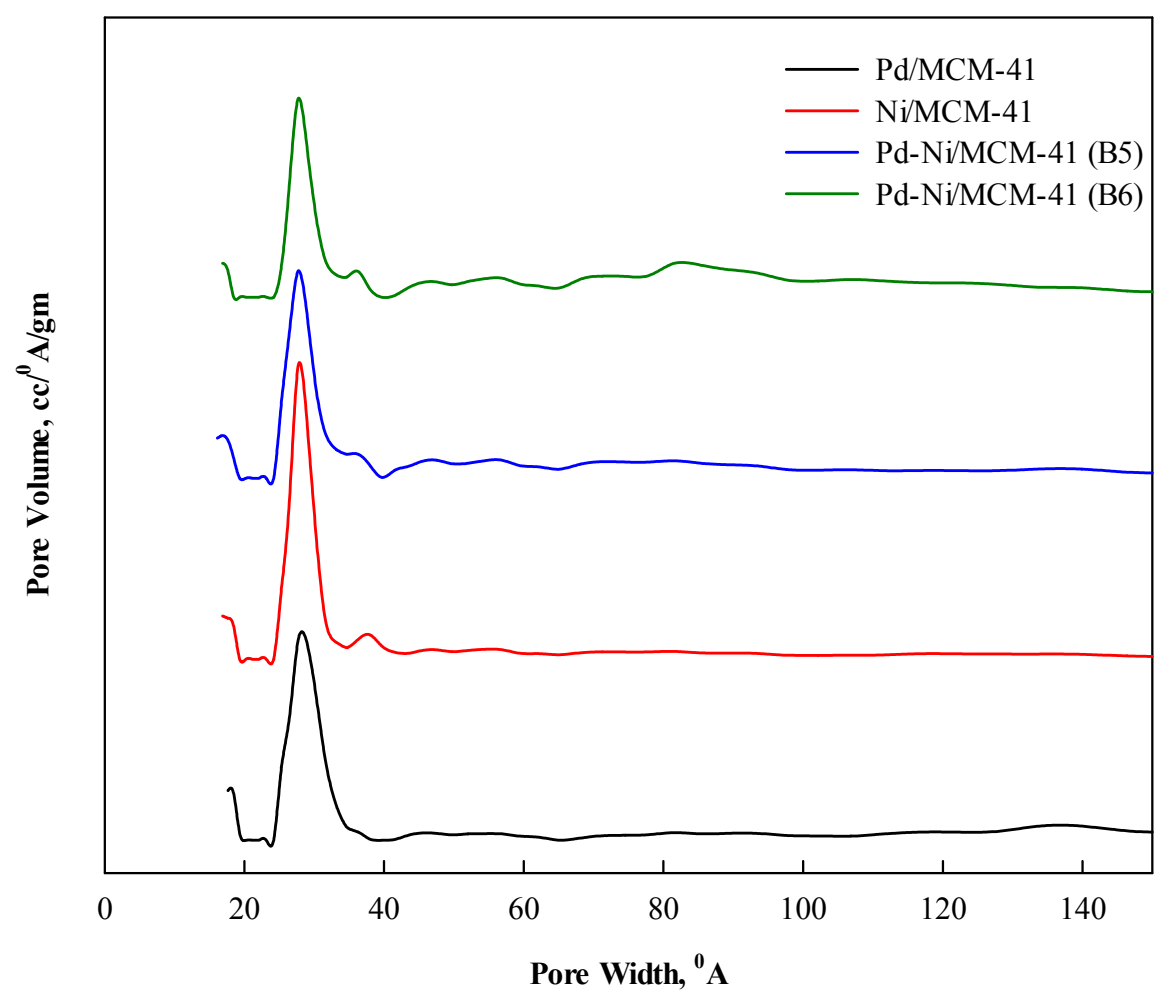

Figure 3.7 The Density Function Theory (DFT) pore size distribution of calcined (a) Pd-MCM41, (b) Ni/MCM-41, (c) Pd-Ni/MCM-41 (B5), (d) Pd-Ni/MCM-41 (B6) 


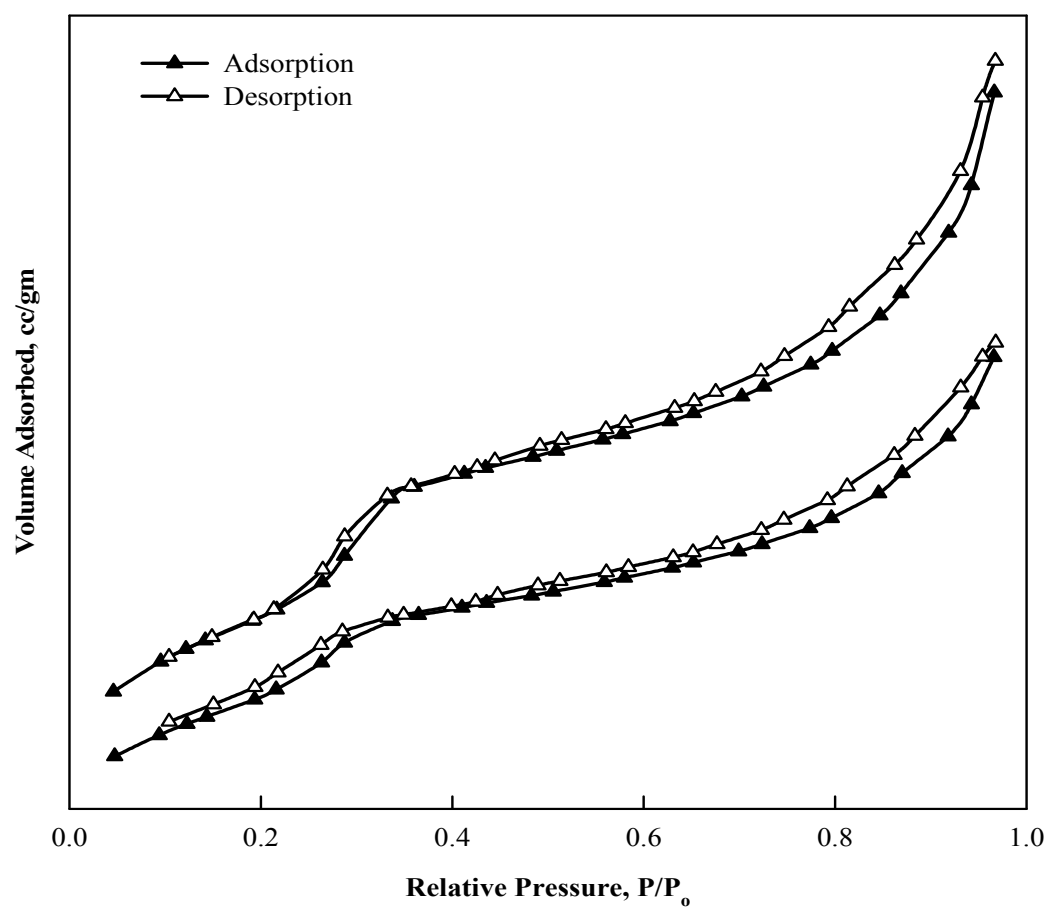

Figure 3.8 $\mathrm{N}_{2}$ adsorption-desorption isotherms of Pd-Ni/MCM-41 (a) as synthesized and (b) calcined samples.

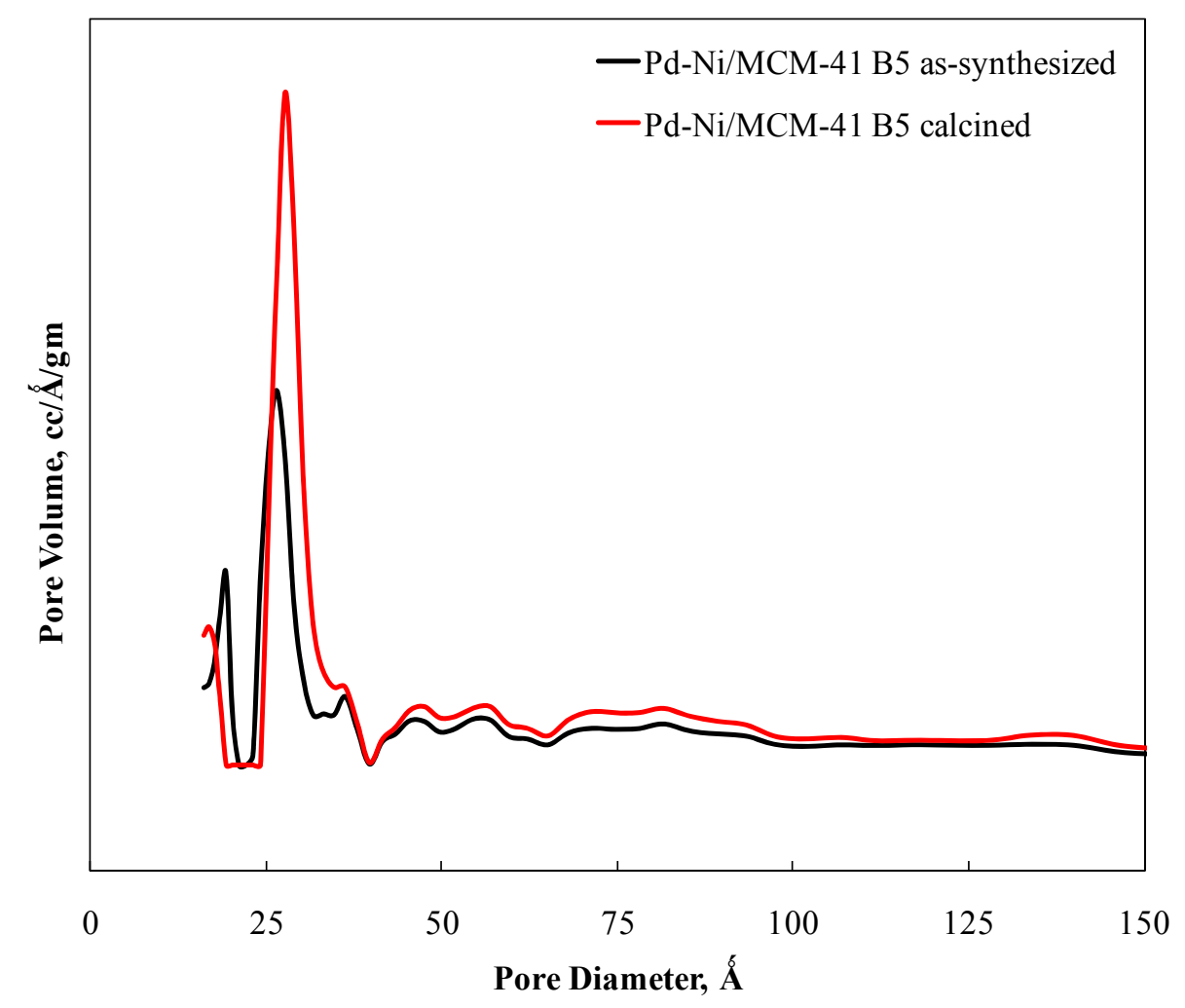

Figure 3.9 The Density Function Theory (DFT) pore size distribution of as-synthesized Pd-Ni(B5) along with Pd-Ni/MCM-41(B5) calcined sample. 


\subsubsection{Fourier Transform Infrared Spectra Analyses}

Infrared spectroscopy has been used extensively for characterization of the transitionmetal cation-modified zeolites. For the FTIR spectra of MCM-41 shown in Figure 3.10 there are two intense bands ( $v_{1}$ and $v_{2}$ ) at 1226 and $1080 \mathrm{~cm}^{-1}$ which are assigned to the asymmetric Si-OSi vibrations. The silanol group stretching vibration $\left(v_{3}\right)$ occurs at $964 \mathrm{~cm}^{-1}$. The band at $806 \mathrm{~cm}^{-1}$ $\left(v_{4}\right)$ is associated with symmetric Si-O-Si stretching and the band at $462 \mathrm{~cm}^{-1}\left(v_{5}\right)$ is assigned to a $\mathrm{SiO}_{4}$ bending mode.

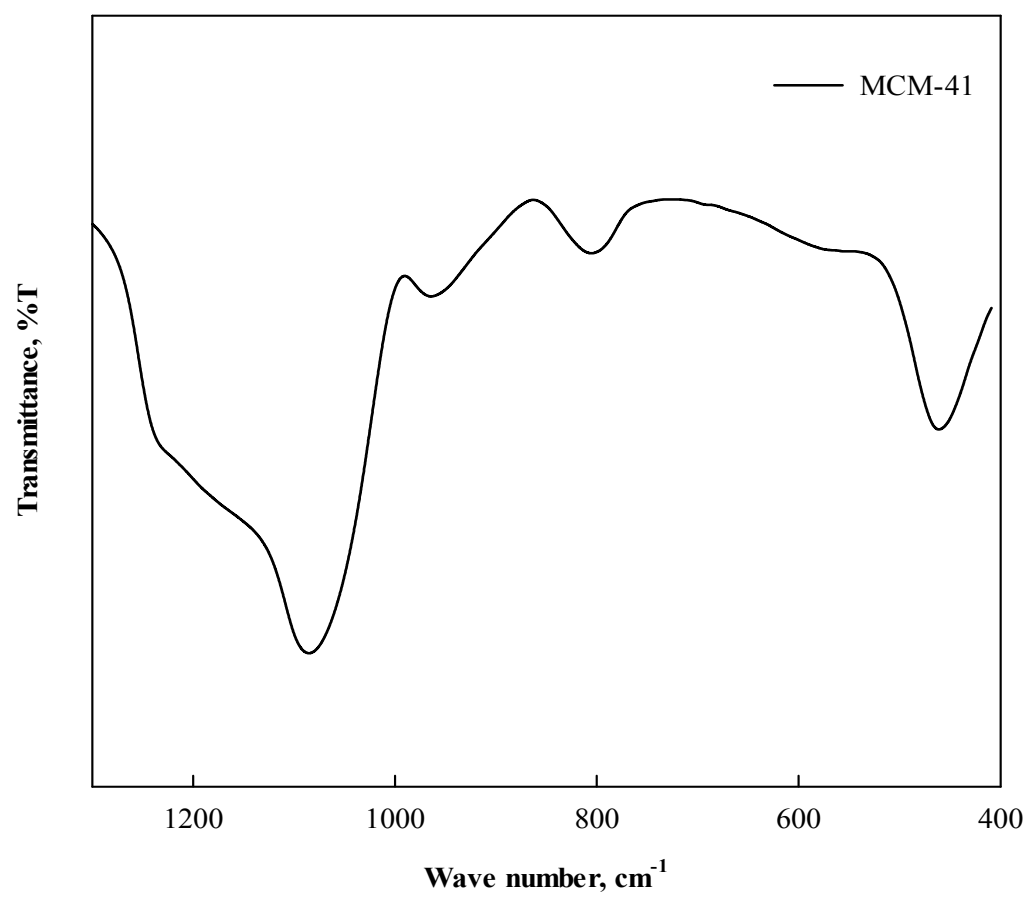

Figure 3.10 FTIR spectrum of MCM-41 after calcination

The calcination effects on Ni/MCM-41 and Pd-Ni/MCM-41 (B6) are shown in Figure 3.11 and Figure 3.12, respectively. For as synthesized M/MCM-41 $(\mathrm{M}=\mathrm{Pd}, \mathrm{Ni})$ samples, similar vibration bands with low intensities were observed. The bands at $720.4 \mathrm{~cm}^{-1}$ and $673.2 \mathrm{~cm}^{-1}$ in the spectrum of as synthesized samples are associated with vibrations of the organic template. The spectrum shows a low intense $v_{3}$ peak which is assigned to $\mathrm{Si}-\mathrm{O}-\mathrm{H}$ or $\mathrm{Si}-\mathrm{OH}$ vibrations. As the heteroatoms were introduced to MCM-41, a slight red shift is observed [46]. The result is due to the generation of extra framework metal species $(\mathrm{Pd}, \mathrm{Ni})$. The spectrum also shows a decrease in wave number of the $v_{2}$ peaks due to the rearrangement of amorphous silicate wall in the precursor species. The IR data of the samples are summarized in Table 3.3. 
The FTIR spectra of all Pd/MCM-41, Ni/MCM-41, and Pd-Ni/MCM-41 samples are quite similar to that of MCM-41. The substitution of silicon by metals (Pd, Ni) causes a shift of the lattice vibration band to a lower wave number. It can be concluded that there is a strong interaction between the atoms of palladium, nickel and silicon etc., suggesting that the heteroatoms are incorporated into the framework of MCM-41 and M-O-Si bonds were formed. The ionic radii of Pd (II) (0.86 $\AA$ ) and Ni (II) (0.69 $\AA$ ) are all larger than Si (IV) (0.26 $\AA$ ) and the length of $\mathrm{M}-\mathrm{O}(\mathrm{M}=\mathrm{Pd}$ and $\mathrm{Ni})$ is greater than that of $\mathrm{Si}-\mathrm{O}$, which led to the decrease of the force constant $(\mathrm{k})$ of the bands. The atomic weights of palladium and nickel were all more than that of silicon, thus the reduced mass $(\mu)$ would increase, and hence the vibration frequencies will decrease. In fact, the data of $\mathrm{a}_{0}$ and $\mathrm{d}_{100}$ obtained from XRD results increased with the heteroatom contents. All the data of IR changed in a systematic way with changes in $\mathrm{M} / \mathrm{Si}$ ratio so as to suggest that Ve-gard's rule was obeyed [47], which further indicated the strong interactions of heteroatoms and silicon, the atoms of palladium and nickel should be in the framework of MCM-41.

Figure 3.13 shows the FT-IR spectra of MCM-41 and Pd-Co-MCM-41. A broad absorption band in the $3000-3500 \mathrm{~cm}^{-1}$ region indicates the presence of $\mathrm{Si}-\mathrm{OH}$ asymmetric stretching. The bands at 1098 and $813 \mathrm{~cm}^{-1}$ for pure MCM-41 arise from the symmetric and asymmetric stretching vibrations of the tetrahedral $\mathrm{SiO}_{4}$ units. We observe two strong bands around 1640 and $1130 \mathrm{~cm}^{-1}$ that may be assigned to symmetric and asymmetric stretching Si-O$\mathrm{Si}$ vibrations. The lower absorption bands at 674 and $586 \mathrm{~cm}^{-1}$ might be assigned to the stretching vibrations of $\mathrm{SiO}_{2}$ tetrahedra and $\mathrm{CoO}_{2}$ and $\mathrm{PdO}_{2}$ units present in the novel materials. The presences of these bands suggest an interaction between hetero atoms and silicon in Si-O-M units. The observed shifts in Pd-Co sample are similar to that observed in silica when hetero atoms such as $\mathrm{Ti}, \mathrm{Sn}$ and $\mathrm{Co}$ are introduced. 


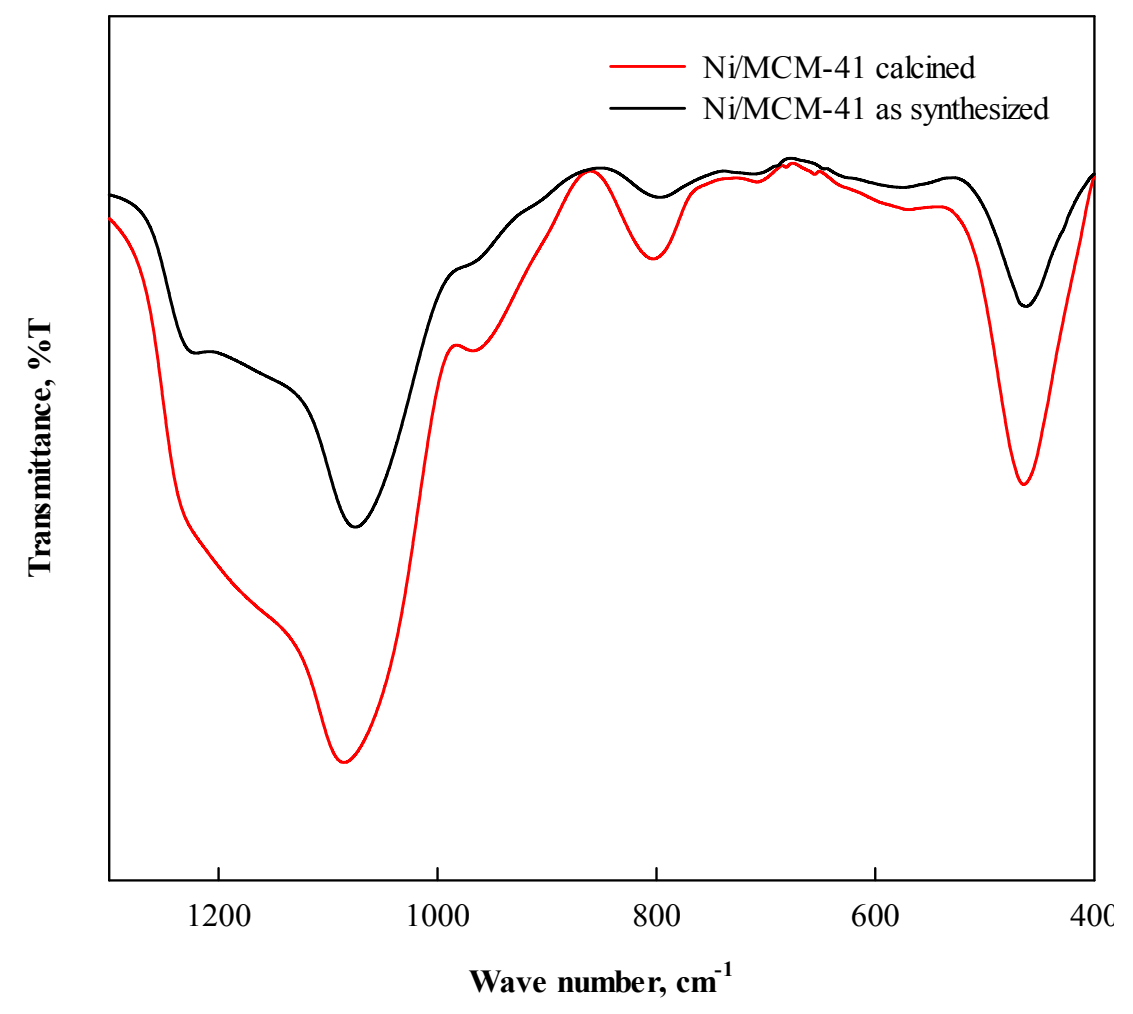

Figure 3.11 FTIR spectra of as synthesized and calcined samples of Ni/MCM-41

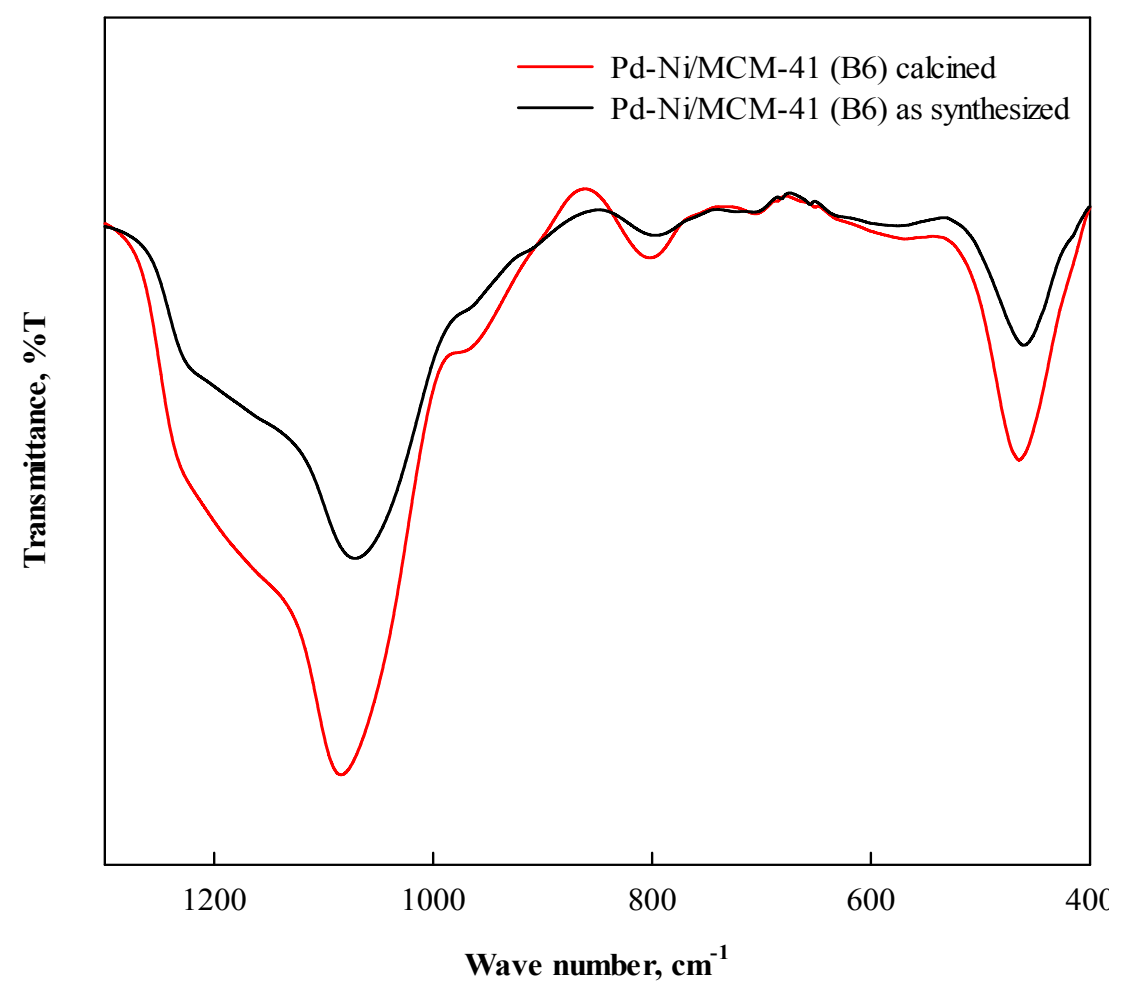

Figure 3.12 FTIR spectra of as synthesized and calcined Pd-Ni/MCM-41 (B6) samples 


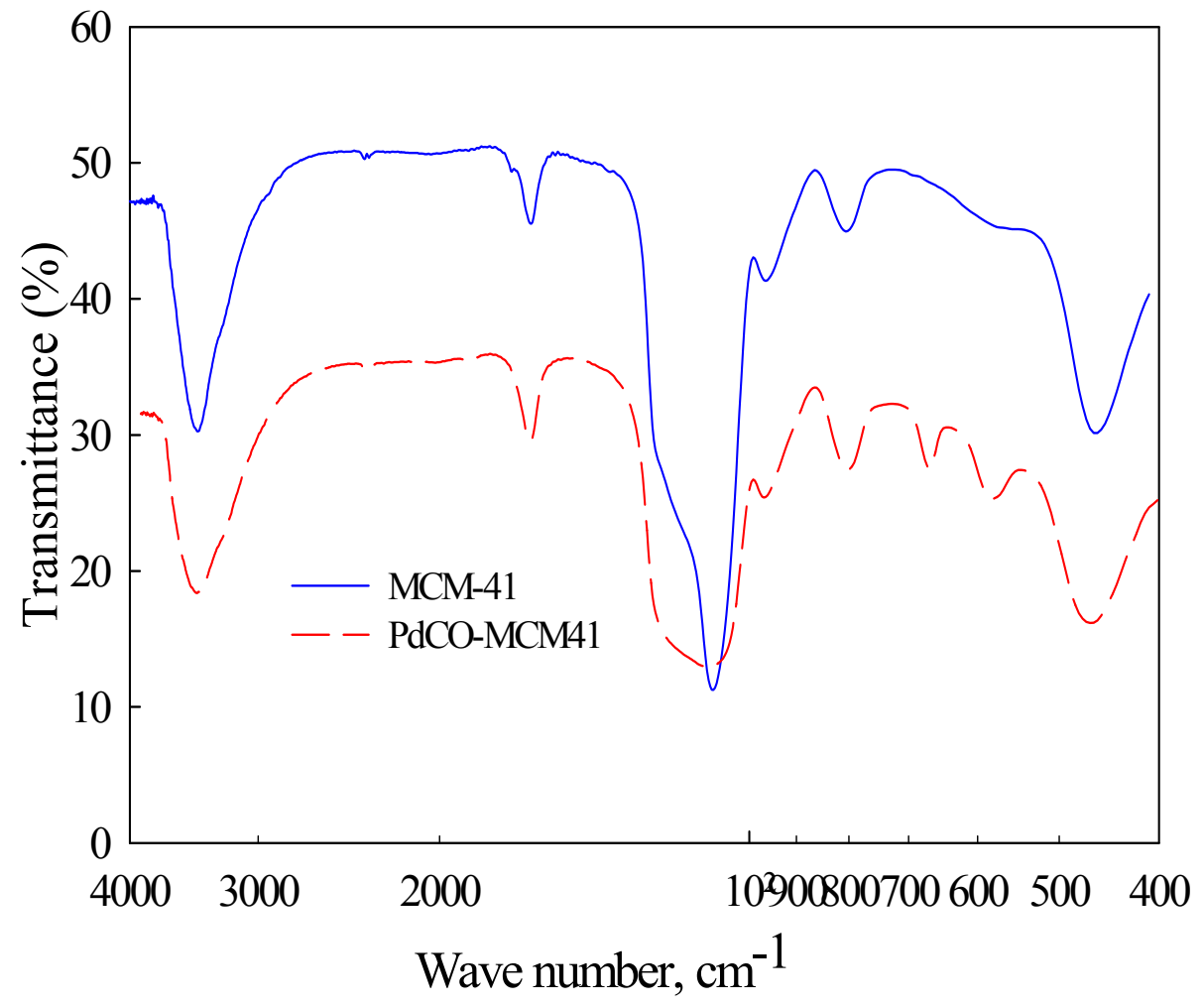

Figure 3.13 FTIR spectra of MCM-41 and Pd-Co-MCM-41

Table 3.3 FT-IR spectra of MCM-41 and M/MCM-41 (M= Pd and Ni).

\begin{tabular}{lccccc}
\hline \multicolumn{1}{c}{ Samples } & \multicolumn{5}{c}{ Wave number, $\left(\mathbf{c m}^{-1}\right)$} \\
\hline MCM-41 & $\left.\mathbf{v}_{\mathbf{1}}\right)$ & $\mathbf{v}_{\mathbf{2}}$ & $\mathbf{v}_{\mathbf{3}}$ & $\mathbf{v}_{\mathbf{4}}$ & $\mathbf{v}_{\mathbf{5}}$ \\
Pd/MCM - 41 & 1226 & 1080 & 965 & 798 & 460 \\
Ni/MCM - 41 & 1222 & 1078 & 958 & 794 & 455 \\
Pd Ni/MCM - 41 (B3) & 1213 & 1075 & 960 & 773 & 460 \\
Pd Ni/MCM - 41 (B4) & 1219 & 1075 & 964 & 796 & 462 \\
Pd Ni/MCM - 41 (B5) & 1219 & 1076 & 956 & 794 & 457 \\
Pd Ni/MCM - 41 (B6) & 1213 & 1078 & 962 & 796 & 459 \\
\hline
\end{tabular}




\subsubsection{High Resolution Transmission Electron Microscopy (HRTEM)}

High resolution TEM (HRTEM) measurements were carried out to confirm the presence of bimetallic nanoparticels and the existence of mesopores in the synthesized materials. The presence of palladium and nickel bi-metallic nanocrystals as black spots on the pore walls of silica is clearly evident in the HRTEM images (Figure 3.14), however they do no block the pores. The bi-metallic particles diffuse into pore walls of silica and their sizes vary from 0.5 to 6 nm.

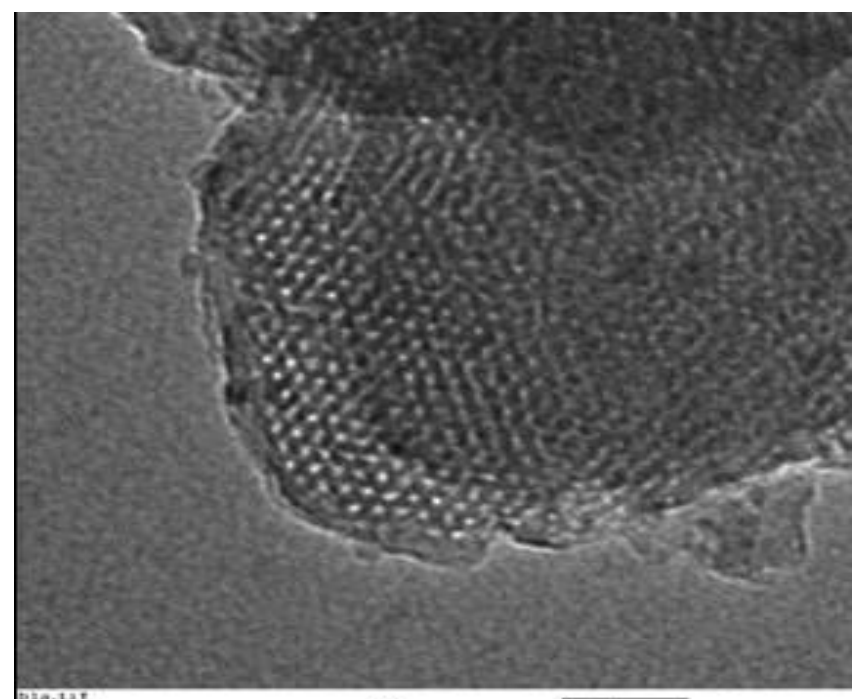

prating

(a)

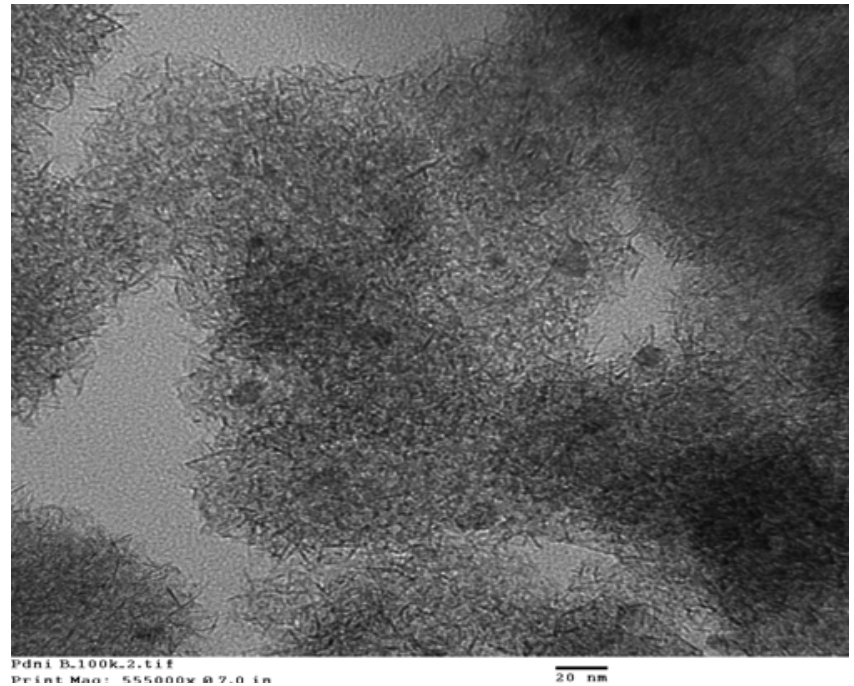

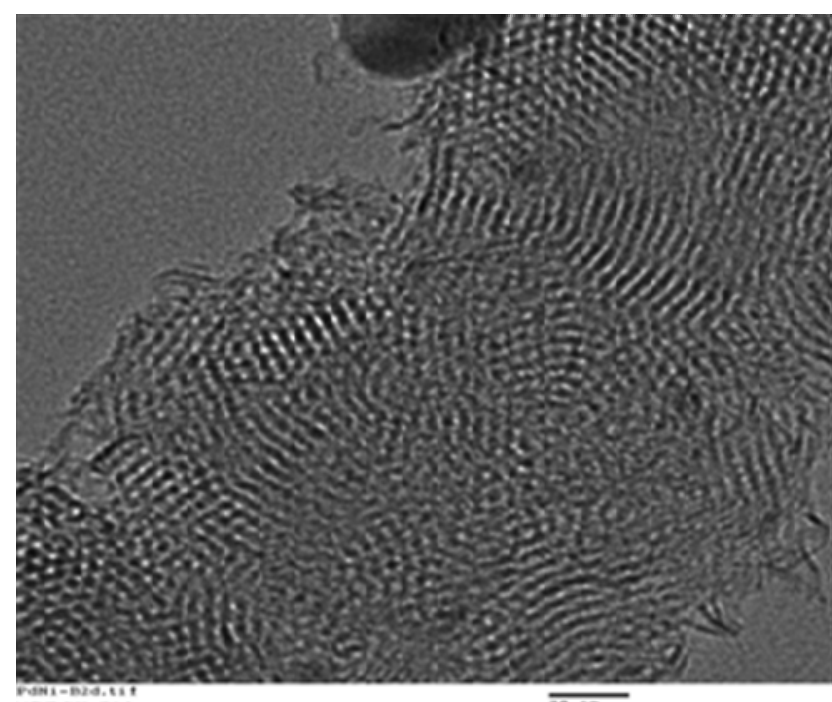

(b)

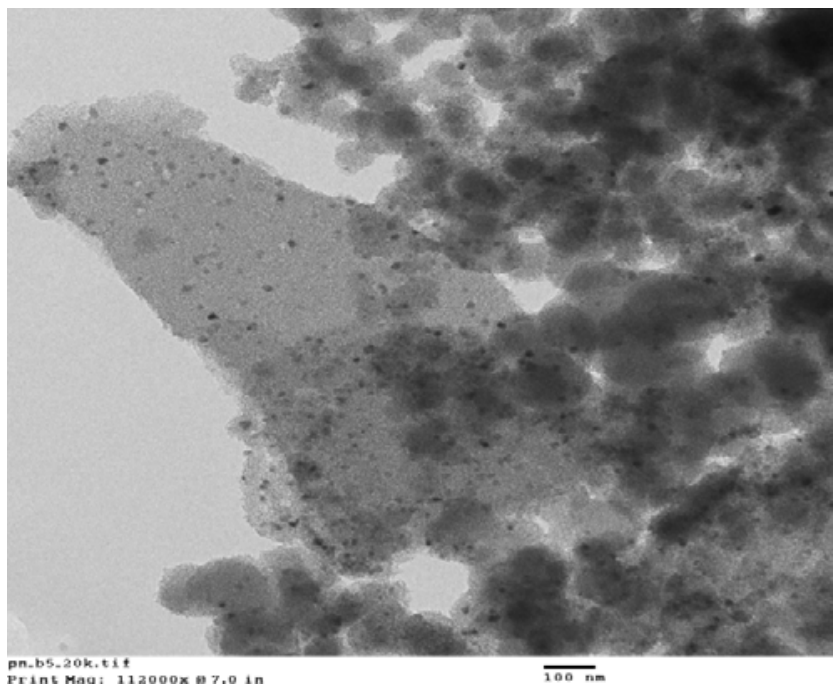

Figure 3.14 TEM images of (a) Pd-Ni/MCM-41 (B1), (b) Pd-Ni/MCM-41 (B2), (c) Pd$\mathrm{Ni} / \mathrm{MCM}-41$ (B5) and (d) Pd-Ni/MCM-41 (B5). 
The particle size distribution is shown in Figure 3.15, about $77 \%$ of the particles are in the range of $0.5-6 \mathrm{~nm}$. The mesoporous structures are partly in random arrangement and the pore sizes in Pd-Ni/MCM-41 sample vary from 2 to $3 \mathrm{~nm}$. The observed disorder is consistent with dspacing values obtained from the small angel XRD studies. The disordered pore arrays, over a large area, is most likely due to in situ synthetic reaction conditions and high concentration of palladium and nickel. Most significantly, the sizes of the palladium and nickel nanoparticles synthesized by in situ hydrothermal procedure are much smaller than the bi-metallic nanoparticels prepared by a two-phase co-gel material composed of silica and a $\mathrm{Pd} / \mathrm{Co}$ cyanogel coordination polymer $[48,49]$. In addition, these nanoparticles synthesized by one-pot procedure are uniformly distributed in mesoporous silica.

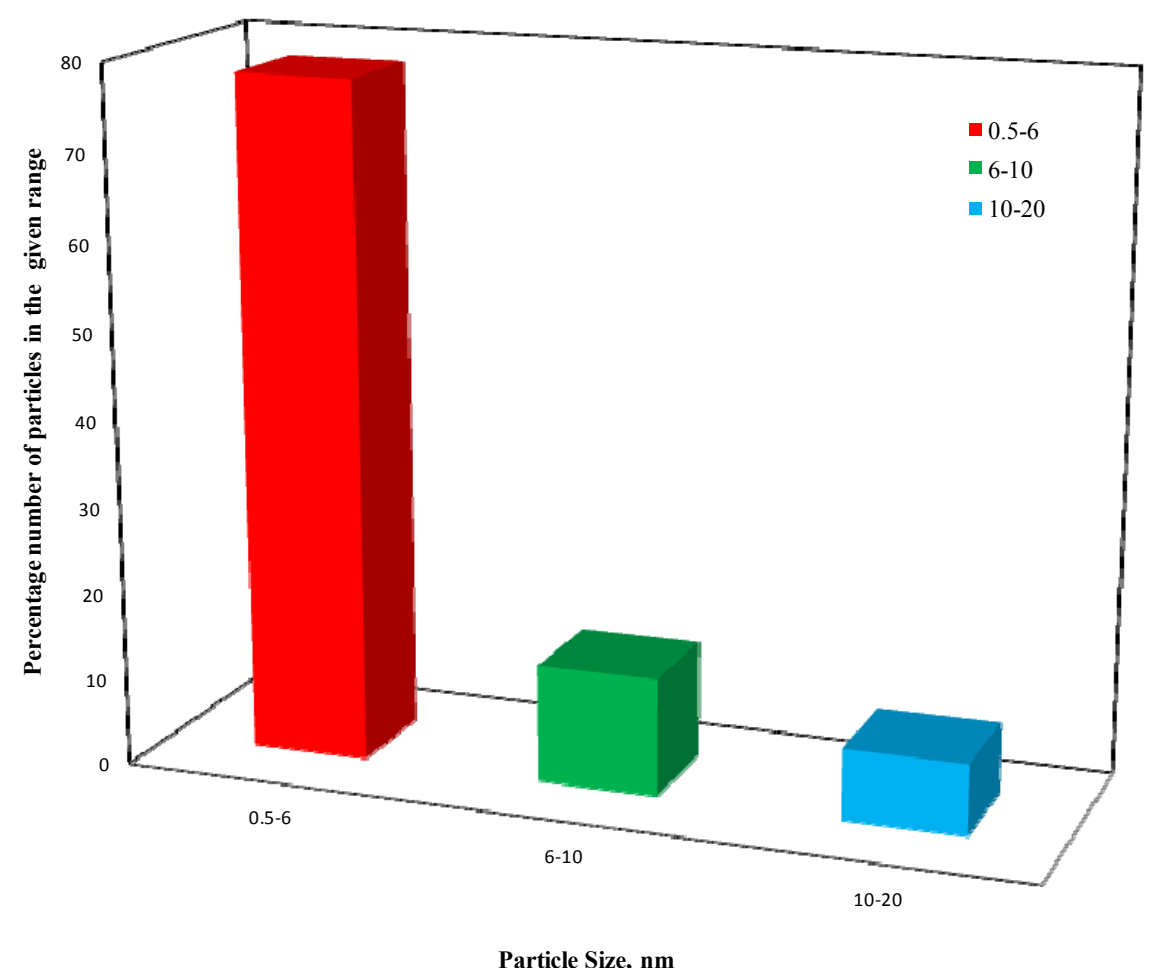

Figure 3.15 Particle size distribution of Pd-Ni/MCM-41 (B4).

The concentration of the palladium and nickel nanoparticles in mesoporous silica were determined by elemental analysis of HRTEM. The analysis was performed with a small electron probe over wide-range domains and over several spots of Pd-Ni/MCM-41 material (Figure 3.16). The elemental analysis further suggests uniform distribution of the bimetallic nanoparticels. As shown in Table 2.1, the weight percentages of palladium and nickel in B4 sample are 2.258 and 
$14.17 \%$ respectively. The EDX data show that the concentration of palladium and nickel are $3.78 \%$ and $14.81 \%$ respectively with respect to silica atoms (by weight) which are consistent with the initial concentration of palladium and nickel precursors. These results also highlight the advantages of this methodology in terms of cost and simplicity for synthesis of uniformly distributed bimetallic nanostructures compared to the synthesized by the chemical vapor deposition technique [8]. Elemental analyses, performed with a small electron probe using the STEM detector over wide-range domains and over several spots of Pd-Co and Pd-Ni-MCM41 materials suggest uniform distribution of the bimetallic nanoparticles. The EDX data show that the concentration of $\mathrm{Co} / \mathrm{Pd}$ and $\mathrm{Ni} / \mathrm{Pd}$ are consistent with the initial concentration of $\mathrm{Pd}-\mathrm{Co}$ and Pd-Ni precursors. The elemental mapping shown in Figure 3.17 further indicates that the metal nanoparticles are uniformly distributed on the surface of silica. These findings suggest the homogeneous dispersion of $\mathrm{Pd}-\mathrm{Co}$ and $\mathrm{Pd}-\mathrm{Ni}$ bimetallic nanoparticles in mesoporous silica.

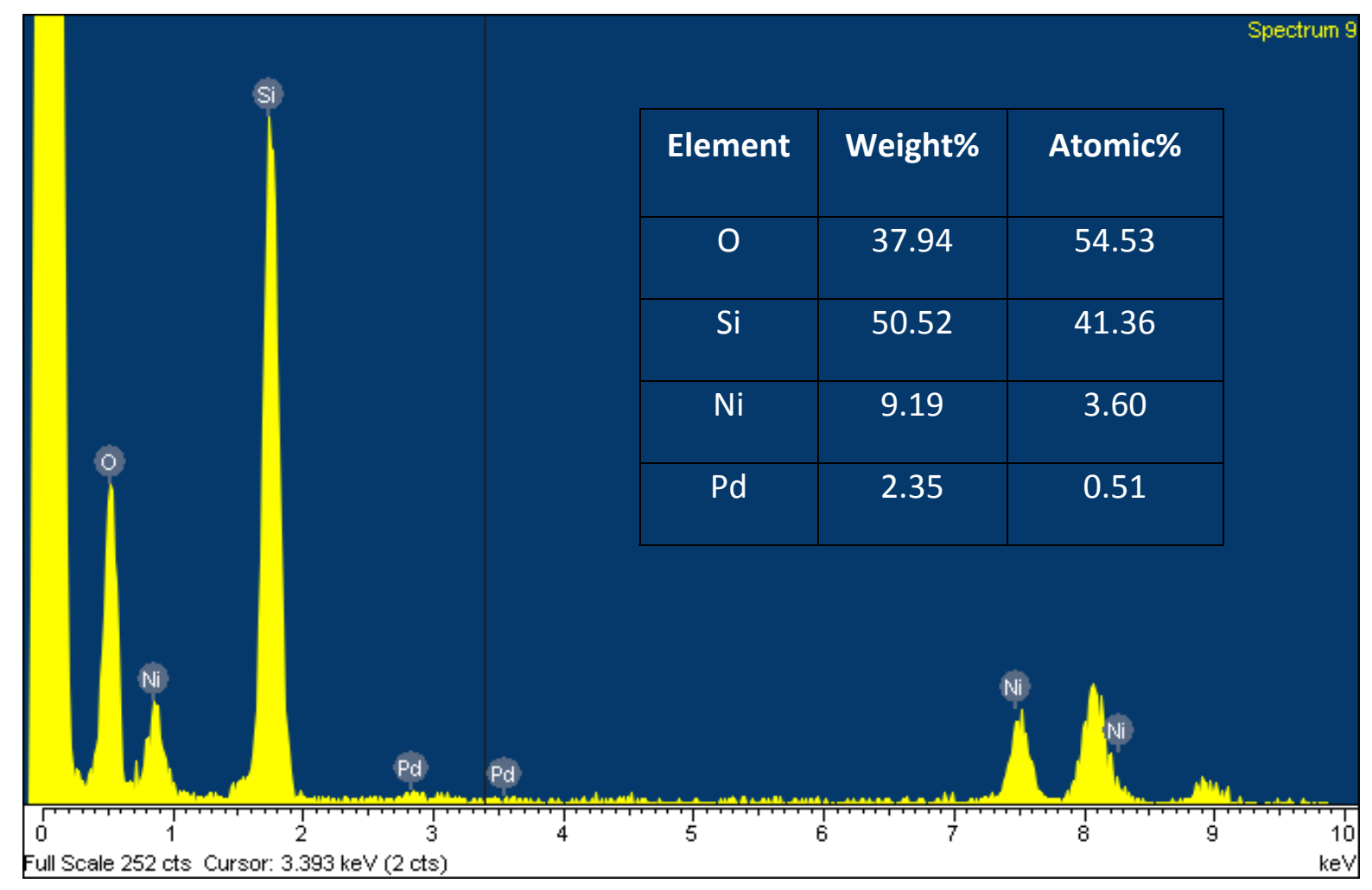

Figure 3.16 The EDX spectrum of Pd-Ni/MCM-41 (B4) sample 

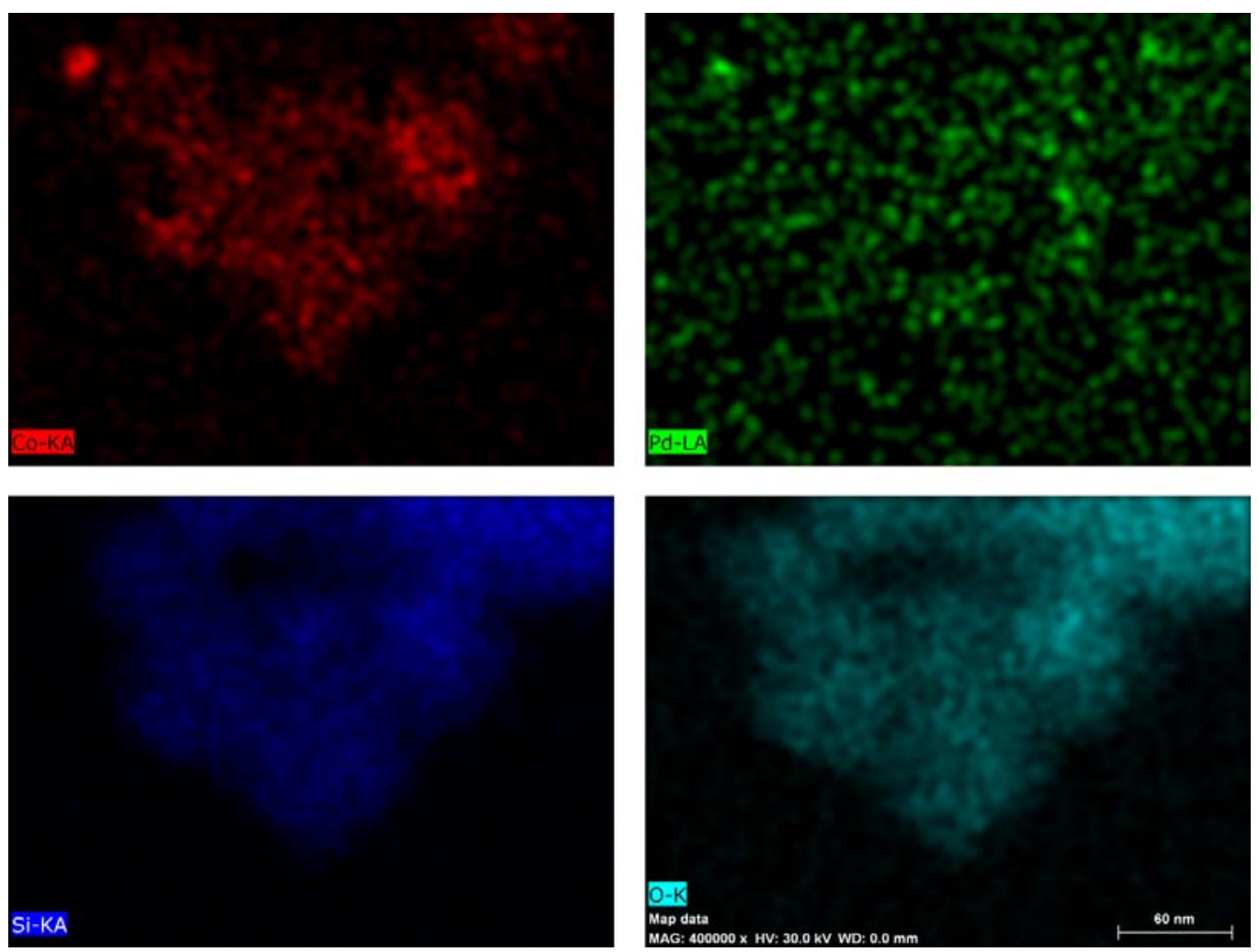

Figure 3.17 Elemental mapping of Pd-Co-MCM-41 sample

\subsubsection{Thermal Gravimetric Analysis (TGA)}

Thermal gravimetric analysis (TGA) was used to investigate the removal of organic template (CTAB) from MCM-41 mesophase under thermal treatment. The TGA curves of MCM-41, Pd/MCM-41, Ni/MCM-41 and Pd-Ni/MCM-41 under airflow are shown in Figure 3.18. The TGA curves of MCM-41 materials are similar to that reported previously in literature $[46,50]$.The thermal analyses of the samples show distinct weight losses which depend on the framework compositions. Three distinct regions of weight loss are in the temperature range of 40 $-150,150-300$ and $300-600{ }^{\circ} \mathrm{C}$. The first weight loss $(3.51-5.52 \%)$ corresponds to desorption, removal of water molecules or ethanol physiosorbed on the external surface of the crystallites or occluded in the macropores, and mesopores present between the crystallite aggregates. 


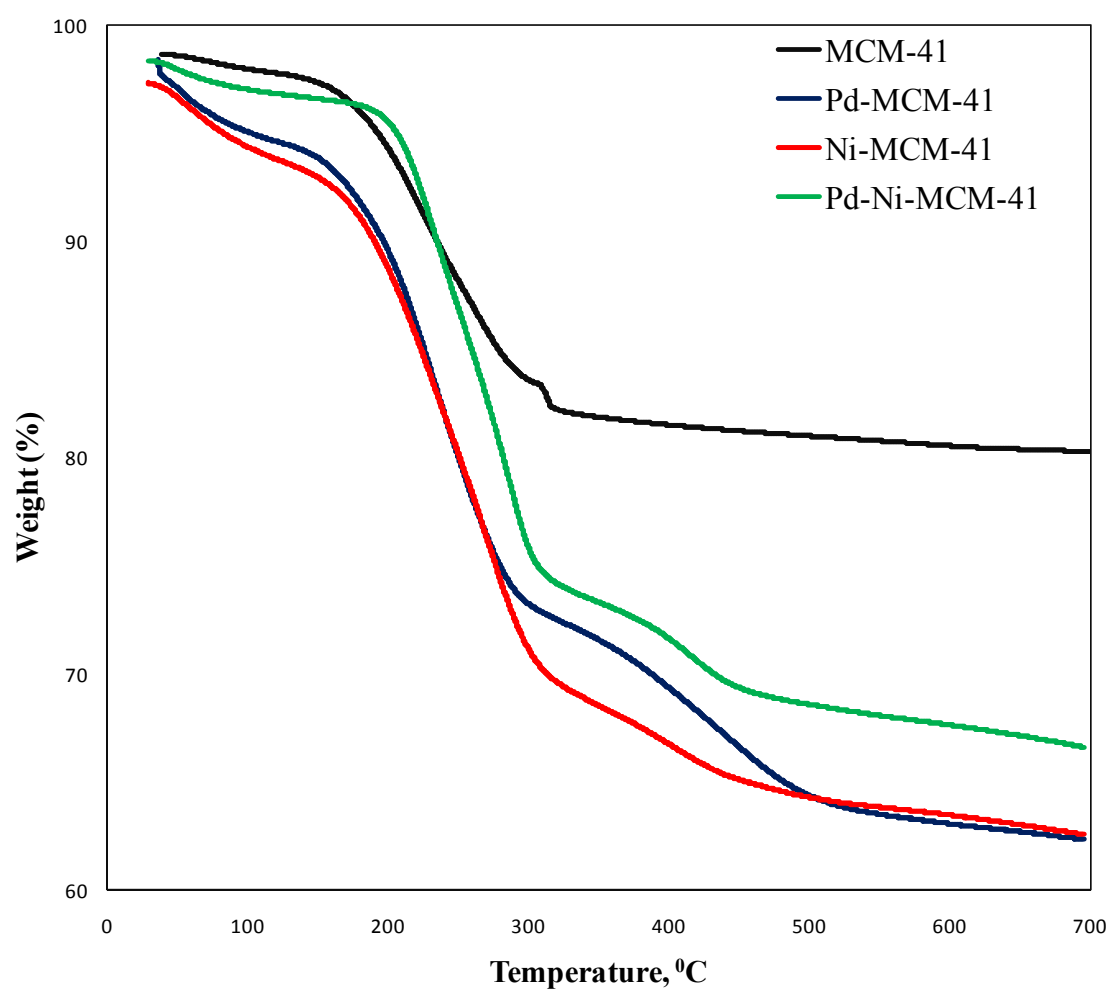

Figure 3.18 TGA curves of single and bi-metallic MCM-41 material

The second weight loss $(14.50-25.51 \%)$ between 150 and $300{ }^{\circ} \mathrm{C}$ is attributed to the removal of the organic template. Finally the third weight loss $(8-9 \%)$ between $300{ }^{\circ} \mathrm{C}$ to $600{ }^{\circ} \mathrm{C}$ is related to water loss from the condensation of adjacent silanol groups to form siloxane bonds [45]. The total weight loss of the M/MCM-41 $(\mathrm{M}=\mathrm{Pd}, \mathrm{Ni})$ materials are in the $20-39 \%$ range. The weight loss distribution depends on the framework or substituted-silicon-to-metals ratios. [37]. Therefore, weight loss was higher in the low-metal-content MCM-41 materials than that in the high-metal-content MCM-41 materials.

\subsection{Catalyst Performance Evaluation for Methanol Steam Reforming}

\subsubsection{Pd-Ni-MCM-41}

Steam reforming of methanol was carried out over single metallic Pd/MCM-41 and Ni/MCM-41 and bimetallic Pd-Ni/MCM-41 (B1) having metal loadings of $8.26 \% \mathrm{Pd}, 5.36 \% \mathrm{Ni}$ and $0.59 \% \mathrm{Pd}, 3.62 \% \mathrm{Ni}$, respectively, as shown in Table 2.1. The SRM reactions were carried out in the temperature range of $250-350{ }^{\circ} \mathrm{C}$ and at reaction flow rates of $0.1,0.2$ and 0.3 $\mathrm{ml} / \mathrm{min}$. The effect of temperature on hydrogen selectivity is shown in Figure 3.19 at three 
different reactant flow rates $(0.1,0.2$, and $0.3 \mathrm{ml} / \mathrm{min})$. The effect of temperature on carbon monoxide selectivity at reactant flow rate $0.1 \mathrm{ml} / \mathrm{min}$ is shown in Figure 3.20. Finally, the effect of temperature on methanol conversion at three different reactant flow rates $(0.1,0.2$ and 0.3 $\mathrm{ml} / \mathrm{min}$ ) is shown in Figure 3.21.

From the SRM experimental results, it can be inferred that the bimetallic Pd-Ni system shows superior performance over individual metal containing catalysts in terms of $\mathrm{H}_{2}$ selectivity and methanol conversion. The selectivity to $\mathrm{H}_{2}$ decreases with increasing temperature due to the endothermic nature of the SRM reaction and decreases with increasing reactant flow rate. The selectivity for $\mathrm{H}_{2}$ with the bimetallic catalyst is much higher than that of the monometallic species. 

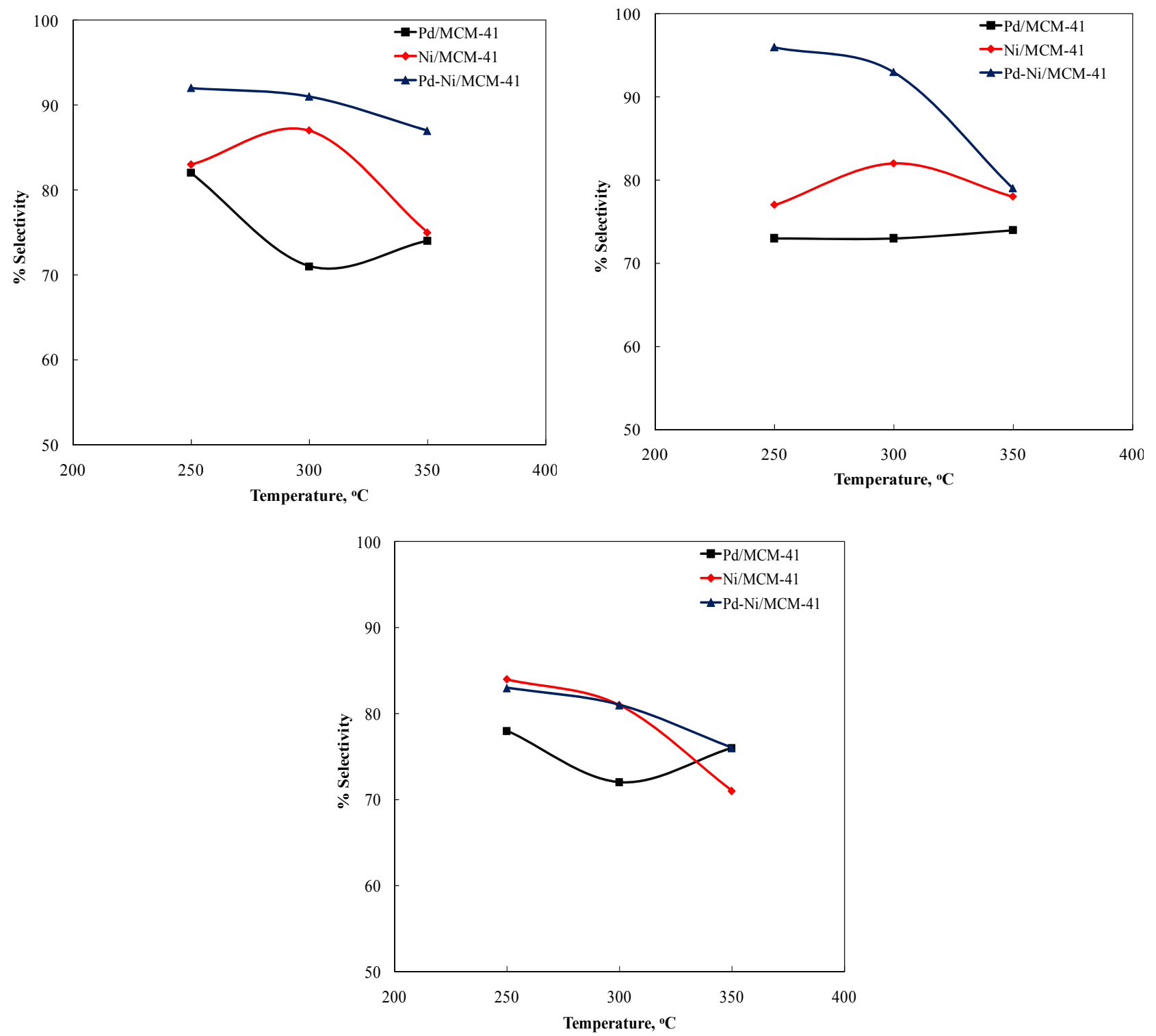

Figure 3.19 Effect of reaction temperature on $\mathrm{H}_{2}$ selectivity over $\mathrm{Pd} / \mathrm{MCM}-41, \mathrm{Ni} / \mathrm{MCM}-41$, and Pd-Ni/MCM-41 (B1) catalyst in SRM reaction at $\mathrm{H}_{2} \mathrm{O} / \mathrm{CH}_{3} \mathrm{OH}$ mole ratio 3 and at reactant flow rate (a) $0.1 \mathrm{ml} / \mathrm{min}$ (b) $0.2 \mathrm{ml} / \mathrm{min}$ and (3) $0.3 \mathrm{ml} / \mathrm{min}$ 


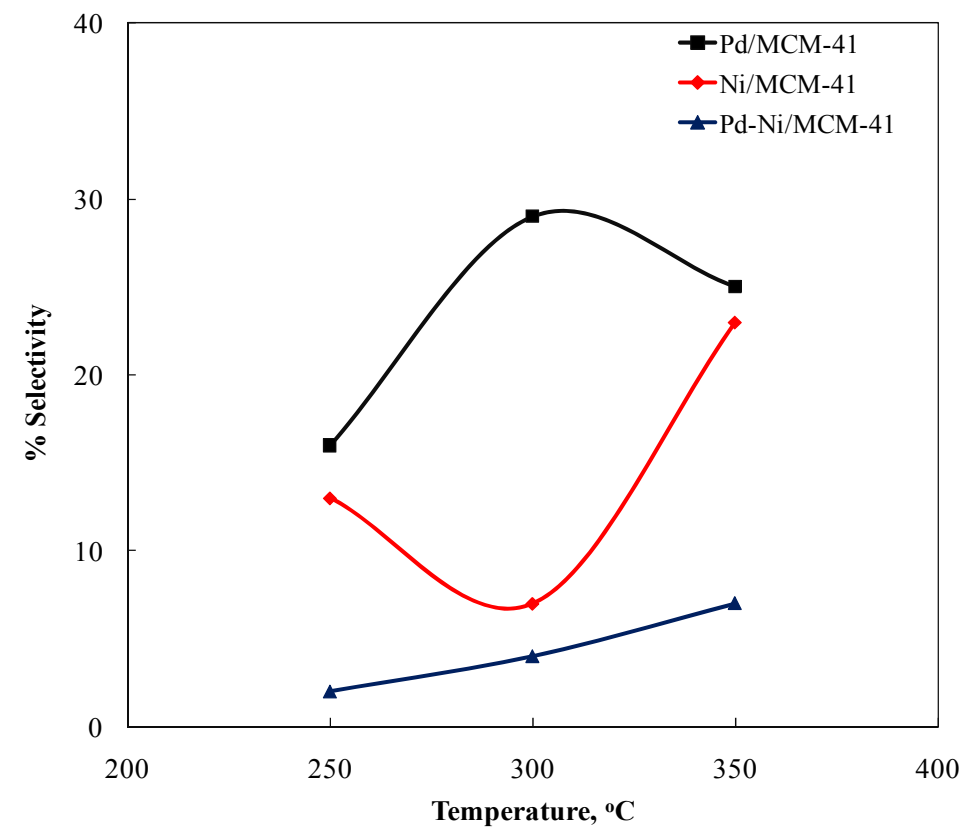

Figure 3.20 Effect of temperature on CO selectivity over Pd/MCM-41, Ni/MCM-41, and Pd$\mathrm{Ni} / \mathrm{MCM}-41$ (B1) catalyst in SRM reaction at $\mathrm{H}_{2} \mathrm{O} / \mathrm{CH}_{3} \mathrm{OH}$ mole ratio 3 and at reactant flow rate $0.1 \mathrm{ml} / \mathrm{min}$. 

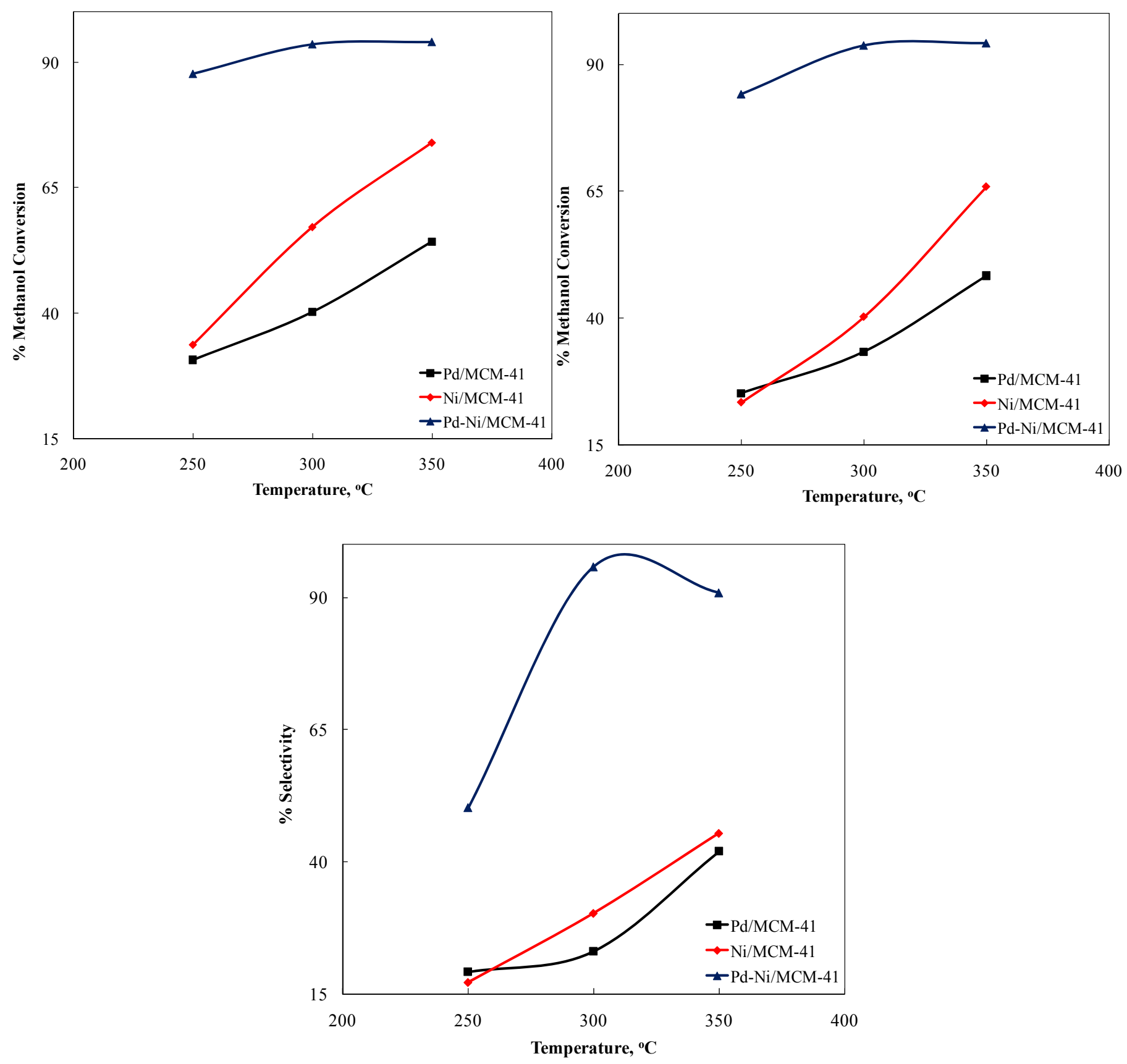

Figure 3.21 Effect of temperature on methanol conversion over Pd/MCM-41, Ni/MCM-41, and $\mathrm{Pd}-\mathrm{Ni} / \mathrm{MCM}-41$ (B1) catalysts in SRM reaction at reactant flow rate (a) 0.1 (b) 0.2 and (c) 0.3 $\mathrm{ml} / \mathrm{min}$. 
Based on the results, presented above, methanol conversion significantly increased after introduction of the second metal (Ni) into the matrix of Pd/MCM-41. For Pd (control), the conversion is $25 \%$, for $\mathrm{Ni}$ (control) it is $20 \%$ at $250 \mathrm{C}$. While the maximum methanol conversion observed for the mono-metallic catalyst was about $74 \%$, about $94 \%$ conversion of methanol was obtained using the Pd-Ni bi-metallic catalyst. These results indicate that the bimetallic system exhibits a synergistic behavior arising from the combination of two metals.

It should be mentioned that although Pd-containing catalyst showed good catalytic activity and high hydrogen production, the formation of much larger amount of byproducts, particularly $\mathrm{CO}$ was observed. The selectivity to $\mathrm{H}_{2}$ improves from $2.2-3.3(\mathrm{Pd})$ and 4-6.5 (Ni) to15-20 for $\mathrm{Pd}-\mathrm{Ni}$ in the temperature range of $250-350^{\circ} \mathrm{C}$. These results suggest that the bimetallic system have the potential in SRM reactions and further systematic studies are necessary to have a better understanding of the bimetallic behavior.

The bimetallic species of Pd-Ni also display exceptional stability and durability in the SRM reactions (based on continuous runs of seven days) carried out in our laboratory. Experiments at higher temperatures show that bimetallic catalyst exhibits thermal stability above $750 \mathrm{~K}$ for a prolonged period of time. Thus, the bimetallic nanocatalysts have potential for steam reforming reactions of ethanol and other biofuels.

\section{Magnetic Measurements of MCM-PdNi to examine its activity after the SRM Reaction.}

It is necessary to develop catalysts that can be recycled or reused. Since the shape and/or crystal anisotropy play an important role in determining the magnetic properties of most fine particles, the magnetization studies on ferromagnetic nanocatalysts can provide an insight on the reducibility and activity of the catalyst during the SRM reactions. The experiments were performed to estimate the catalyst's activity from the saturation magnetization value of the ferromagnetic component obtained at different stages of SRM studies.

The magnetization curve (Figure 3.22) of the Pd-Ni nanocatalyst before the SRM reaction shows the ferromagnetic behavior of the catalyst revealing that most of the catalyst is reduced by hydrogenation from oxides to pure metals, the active phase for the SRM reaction. The magnetization experiments after the SRM reaction still shows the ferromagnetic nature of the catalyst (Figure 3.22), demonstrating that the metal component is not deactivated even after the longest run of the SRM reaction. This is consistent with conversion and selectivity for $\mathrm{H}_{2}$ 
production, described above. The stability of the PdNi bimetallic catalyst is superior to that observed in our previous studies in sol-gel matrix with Fe-Co-Ru catalysts for Fischer-Tropsch reactions and $\mathrm{Co}$ or Ni catalysts for the SRM reactions. In both cases, the sol-gel encapsulated catalysts deactivated more easily [1]. The current results are indeed significant and suggest the stability of the Pd-Ni catalyst in mesoporous silica. This property along with its thermal stability will be useful for $\mathrm{H}_{2}$ production from other biofuel such as bioethanol.

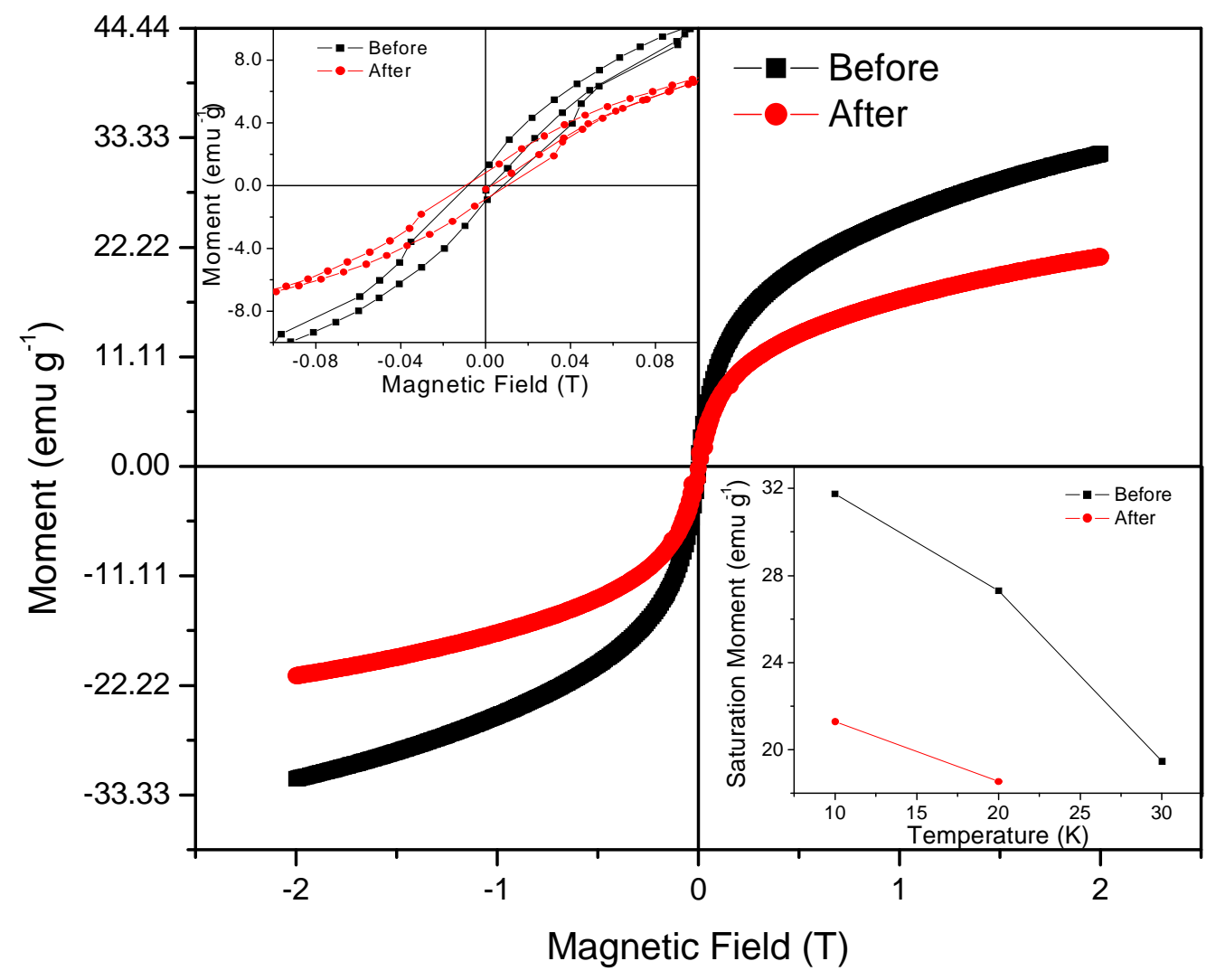

Figure 3.22 Magnetic data for PdNi in mesoporous silica before and after SRM reaction. The lower Inset shows increase of saturation moment at lower temperature.

\subsubsection{Pd-Co-MCM-41}

In our initial experiments, the conversion of methanol increased with increase in temperature for Pd and it decreased for Co (not shown). In general, steam reforming of methanol is done at temperature below $200^{\circ} \mathrm{C}$. However, it was difficult to observe any pressure build-up to produce $\mathrm{H}_{2}$ in our tubular reactor at low temperature. So, the reactions were carried out at 
higher temperature. The methanol conversion for Pd-MCM-41 increases with the increase of temperature. The conversion is higher at lower flow rate at all three different temperatures, and a maximum of $60 \%$ conversion is observed at $350^{\circ} \mathrm{C}$ for $0.1 \mathrm{~mL} / \mathrm{min}$ flow rate. The methanol conversion for Co-MCM-41 decreases with an increase in temperature and it is in contrast to conversion with Pd-MCM-41 at higher temperature. We speculate that there are side reactions in the presence of cobalt that becomes significant at higher temperature. The maximum conversion at flow rate of $0.1 \mathrm{~mL} / \mathrm{min}$ for Co-MCM- 41 is $40.96 \%$ at $250^{\circ} \mathrm{C}$.

Our initial results on conversion of methanol for Pd-Co/MCM-41 (B4) (not shown) was higher compared to individual Pd-MCM-41 and Co-MCM-41. With an increase in temperature, the methanol conversion decreased and it was dominated by the contribution of Co-MCM-41. The maximum conversion for Pd-Co/MCM-41 (B4) is $52.7 \%$ at $250^{\circ} \mathrm{C}$ with $0.1 \mathrm{~mL} / \mathrm{min}$ flow rate. The methanol conversion for $\mathrm{Pd}-\mathrm{Co} / \mathrm{MCM}-41$ (B6) decreases with an increase in temperature. The maximum conversion Pd-Co/MCM-41 (B6) was $23.1 \%$ at $250^{\circ} \mathrm{C}$ with 0.1 $\mathrm{mL} / \mathrm{min}$ flow rate. Except at $350^{\circ} \mathrm{C}$, the conversion is higher at low flow rate as expected. The results suggest that higher palladium concentration along with cobalt gives lesser methanol conversion and whereas smaller amount of palladium significantly improves the catalytic properties of cobalt. We observe that low metal loading in Pd-Co/MCM-41 (B6) leads to lower conversion compared to individual Pd-MCM-41 and Co-MCM-41. Similarly higher palladium concentration in Pd-Co/MCM-41 (B6) significantly hinders the catalytic properties of cobalt. These studies seem to suggest that these catalysts are better to be used at lower temperature with a lower flow rate for production of hydrogen from methanol.

We were puzzled with our initial results presented above. In order to understand the $\mathrm{H}_{2}$ production results using Pd-Co-MCM-41 better, we performed new experiments with Pd and Cosalts again. The results are shown in the Figures below. We compare the results from individual metal with Pd-Co bimetallic species in mesoporous silica in the temperature range of 250-350 as shown in Figure 3.23. 


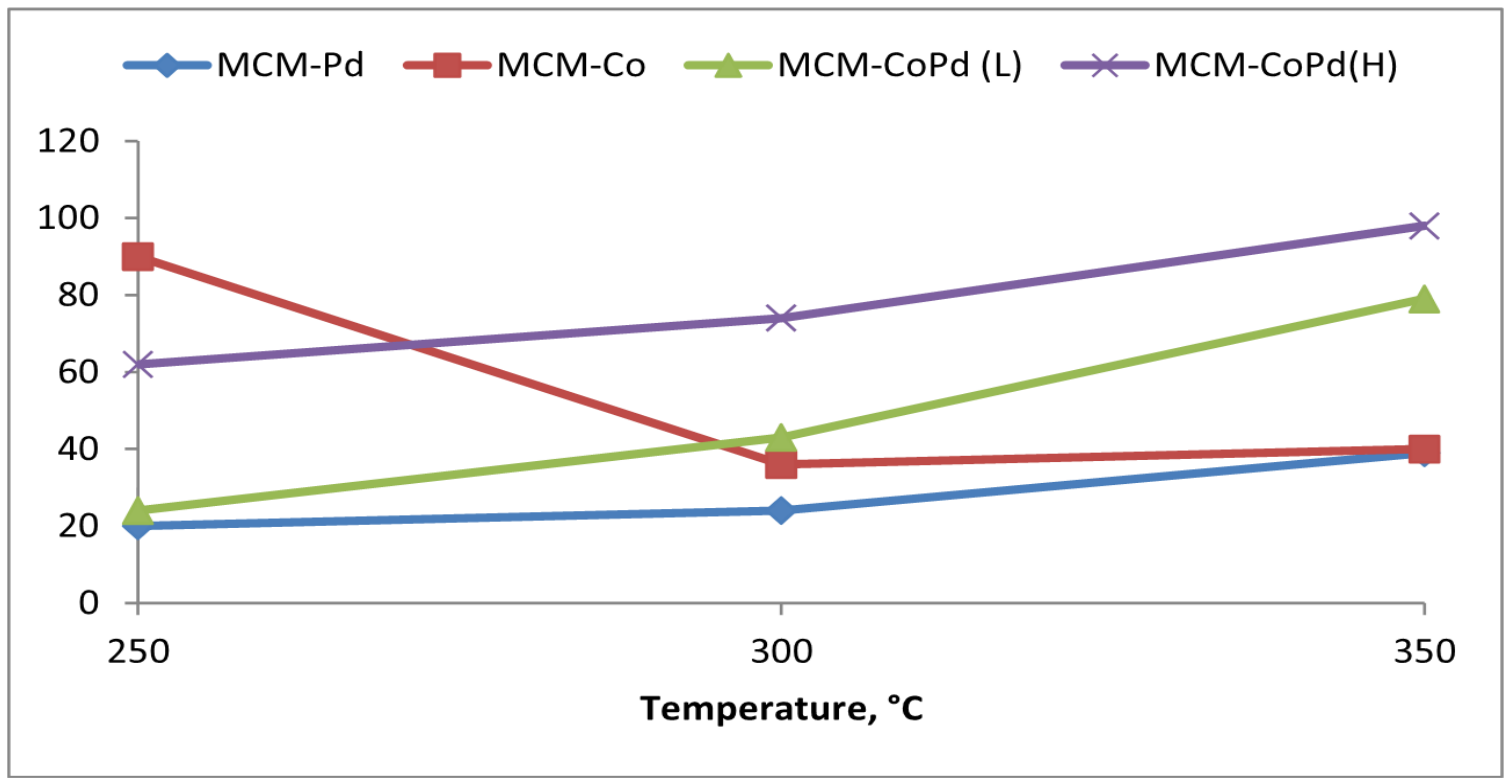

Figure 3.23 MeOH Conversion using MCM-Co, MCM-Pd, MCM-CoPd (H orB4), MCM-CoPd (L or B6) in SRM reactions; flow rate $0.2 \mathrm{ml} / \mathrm{min}$.

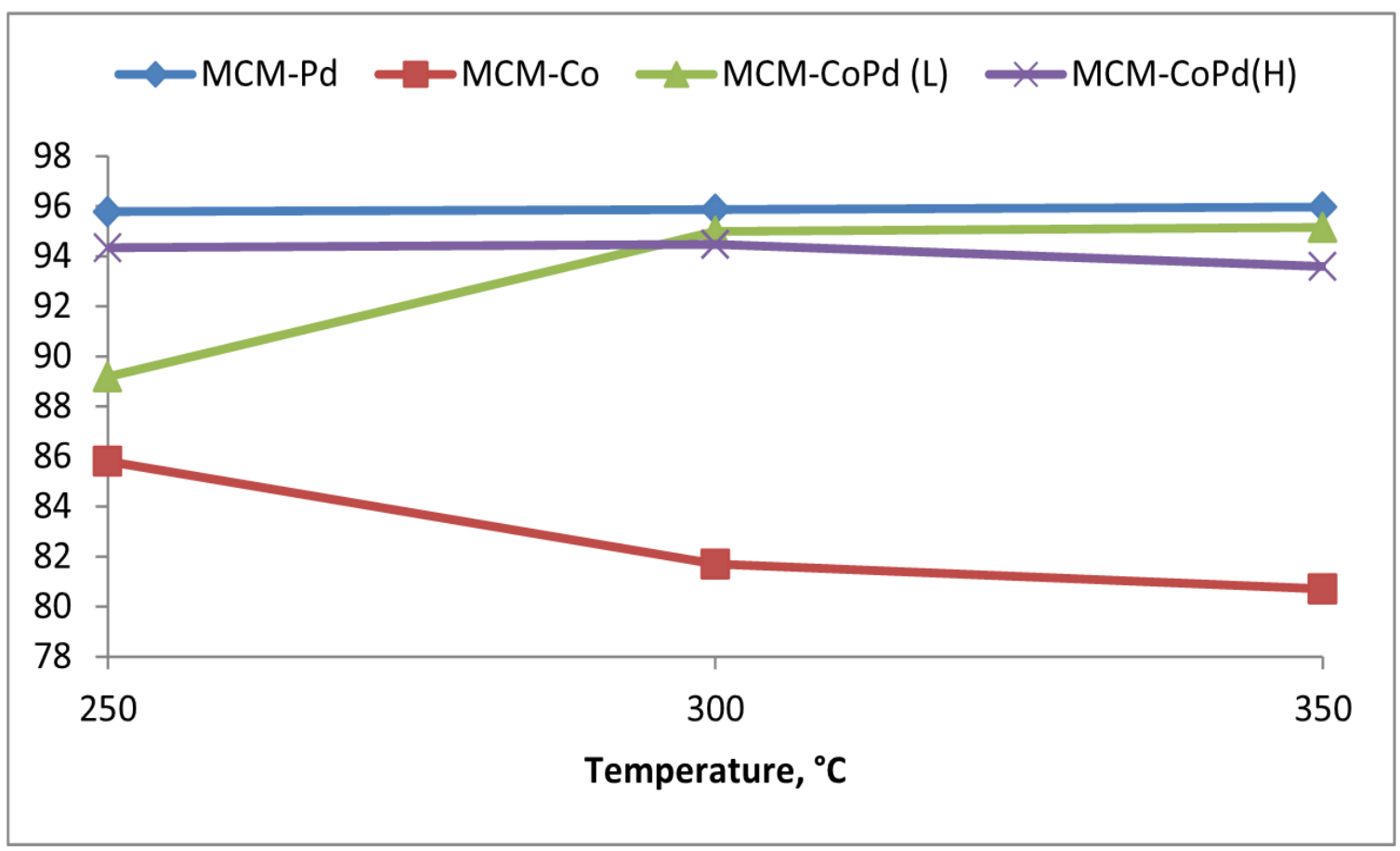

Figure 3.24 $\mathrm{H}_{2}$ Selectivity for MCM-Co, MCM-Pd, MCM-CoPd (H or B4), MCM-CoPd (L or B6) in SRM reactions; flow rate, $0.2 \mathrm{ml} / \mathrm{min}$. 
Figure 3.23 shows the effect of temperature on the conversion of methanol on Co/MCM41, Pd/MCM-41, Co-Pd (H)/MCM-41 and Co-Pd (H)/MCM-41 catalysts. Methanol conversion for Co goes down with increasing temperature while for Pd alone it slightly increases and essentially remains constant. For bimetallic species of MCM-PdCo, there is a gradual increase in conversion of methanol with temperature at both higher $(\mathrm{H})$ and lower $(\mathrm{L})$ loadings of Pd-Co bimetallic species. The selectivity for $\mathrm{H}_{2}$ production for these catalysts is shown in Figure 3.24. While the selectivity remains constant for Pd and Pd:Co bimetallic system with increase in temperature, the selectivity is much lower for cobalt and it decreases with increase in temperature. Thus, Co does not appear to be a good catalyst for steam reforming reactions at higher temperature.

\section{CONCLUSION AND RECOMMENDATIONS}

\subsection{Conclusions}

We have synthesized MCM-41 mesoporous silica containing bimetallic nanocatalysts of $\mathrm{Pd}-\mathrm{Ni}$ and Pd-Co using one-pot hydrothermal procedure developed in our laboratory. The HRTEM along with XRD and nitrogen adsorption-desorption studies confirm the existence of an ordered mesoporous structure with pore sizes ranging from $2-3 \mathrm{~nm}$. While the FT-IR studies indicate that the metal nanoparticles are successfully incorporated into the MCM-41 structure, the EDX analysis and mapping show a uniform distribution of metals. The size of the metal nanoparticles is in the range of 1 to $6 \mathrm{~nm}$.

The bimetallic catalysts are active in steam reforming of methanol reactions to produce $\mathrm{H}_{2}$. The catalytic activity studies for the SRM reactions show a synergistic behavior for the bimetallic nanocatalysts with high methanol conversion and superior selectivity compared to the catalysts containing individual metals, more specifically with Pd-Ni- MCM-41. The results of our studies demonstrate that mesoporous silica supported bimetallic nanocatalysts can be used for $\mathrm{H}_{2}$ production by steam reforming reactions. The Pd-Ni bimetallic nanocatalyst also showed excellent thermal stability and activity after SRM reactions. Thus, the bimetallic nanocatalysts in mesoporous silica have potential for $\mathrm{H}_{2}$ production from biofuels to provide a solution to the energy and green chemistry challenges and can be used for high temperature steam reforming of other alcohols. 


\subsection{Recommendations for future work}

To develop MCM-41 encapsulated bimetallic nanocatalysts further and demonstrate their technical viability, the following future work can be suggested:

- The metal loading in MCM-41 matrix is very important for SRM reactions. At higher metal loadings, the MCM-41 structure collapses. So, a detailed study is needed to find the threshold of total metal loading where the MCM-41 structure is retained.

- Different mesoporous support materials in combination with bimetallic/trimetallic systems containing non-precious metals should be investigated.

This work has generated one MS Thesis, 10 conference presentations (\& abstracts) and one publication.

\section{ACKNOWLEDGEMENT}

This research was sponsored by the Pittsburgh Energy Technology Center, U.S. Department of Energy, under Award Number DE-FG26-09NT0008066. Mr. Richard Dunst., NETL, Pittsburgh, PA is the DOE Project Officer. The opinions, findings, and conclusions, or recommendations expressed in this report are those of the author and do not reflect the views of the DOE. Analytical support from the Center for Advanced Materials and Smart Structures (CAMSS) of North Carolina A\&T State University is gratefully acknowledged with special thanks to Drs. Jag Sankar, D. Kumar and Sergey Yarmolenko. We also thank Dr. Vishwanath Deshmane for his help to prepare this final report.

\section{REFERENCES}

[1] Zhao, S., Nagineni, V. S., Seetala, N. V., and Kuila, D., "Microreactors for Syngas Conversion to Higher Alkanes: Effect of Ruthenium on Silica-Supported Iron-Cobalt Nanocatalysts," Industrial \& Engineering Chemistry Research, 47, 1684 (2008).

[2] Schulz, H., "Short history and present trends of Fischer-Tropsch synthesis," Applied Catalysis A: General, 186, 3 (1999).

[3] Pettersson, L. and Sjöström, K., "Onboard hydrogen generation by methanol decomposition for the cold start of neat methanol engines," International Journal of Hydrogen Energy, 16, 671 (1991). 
[4] De Wild, P. J. and Verhaak, M. J. F. M., "Catalytic production of hydrogen from methanol," Catalysis Today, 60, 3 (2000).

[5] Amphlett, J. C., Evans, M. J., Jones, R. A., Mann, R. F., and Weir, R. D., "Hydrogen production by the catalytic steam reforming of methanol part 1: The thermodynamics," The Canadian Journal of Chemical Engineering, 59, 720 (1981).

[6] Zhao, S. and Kuila, D., "Nanocatalysis in Microreactor for Fuels," in Microfluidic Devices in Nanotechnology: Applications, ed: John Wiley \& Sons, Inc, (2010)

[7] Iwasa, N., Masuda, S., Ogawa, N., and Takezawa, N., "Steam reforming of methanol over $\mathrm{Pd} / \mathrm{ZnO}$ : Effect of the formation of $\mathrm{PdZn}$ alloys upon the reaction," Applied Catalysis A: General, 125, 145 (1995).

[8] Schmid, G., Nanoparticles: From Theory to Application, Wiley-VCH, (2004).

[9] Fendler, J. H., Nanoparticles and nanostructured films, Weinheim, Wiley-VCH, (1998).

[10] Ferrando, R., Jellinek, J., and Johnston, R. L., "Nanoalloys: From Theory to Applications of Alloy Clusters and Nanoparticles," Chemical Reviews, 108, 845 2008/03/01 (2008).

[11] Ferey, G., "Hybrid porous solids: past, present, future," Chemical Society Reviews, 37, 191 (2008).

[12] Aprile, C., Abad, A., García, H., and Corma, A., "Synthesis and catalytic activity of periodic mesoporous materials incorporating gold nanoparticles," Journal of Materials Chemistry, 15, 4408 (2005).

[13] Beck, J. S., Vartuli, J. C., Roth, W. J., Leonowicz, M. E., Kresge, C. T., Schmitt, K. D., Chu, C. T. W., Olson, D. H., and Sheppard, E. W., "A new family of mesoporous molecular sieves prepared with liquid crystal templates," Journal of the American Chemical Society, 114, 10834 (1992).

[14] Kresge, C. T., Leonowicz, M. E., Roth, W. J., Vartuli, J. C., and Beck, J. S., "Ordered mesoporous molecular sieves synthesized by a liquid-crystal template mechanism," Nature, 359, 710 (1992).

[15] Chen, L. Y., Jaenicke, S., and Chuah, G. K., "Thermal and hydrothermal stability of framework-substituted MCM-41 mesoporous materials," Microporous Materials, 12, 323 (1997). 
[16] Kosslick, H., Lischke, G., Walther, G., Storek, W., Martin, A., and Fricke, R., "Physicochemical and catalytic properties of Al-, Ga- and Fe-substituted mesoporous materials related to MCM-41," Microporous Materials, 9, 13 (1997).

[17] Corma, A., "From microporous to mesoporous molecular sieve materials and their use in catalysis," Chemical Reviews, 97, 2373 (1997).

[18] Corma, A., "Solid acid catalysts," Current Opinion in Solid State and Materials Science, 2, 63 (1997).

[19] Tanev, P. T. and Pinnavaia, T. J., "Mesoporous Silica Molecular Sieves Prepared by Ionic and Neutral Surfactant Templating: A Comparison of Physical Properties," Chemistry of Materials, 8, 2068 (1996).

[20] Xia, Q. H., Hidajat, K., and Kawi, S., "Adsorption and catalytic combustion of aromatics on platinum-supported MCM-41 materials," Catalysis Today, 68, 255 (2001).

[21] Long, R. and Yang, R., "Pt/MCM-41 catalyst for selective catalytic reduction of nitric oxide with hydrocarbons in the presence of excess oxygen," Catalysis Letters, 52, 91 (1998).

[22] Junges, U., Jacobs, W., Voigt-Martin, I., Krutzsch, B., and Schüth, F., "MCM-41 as a support for small platinum particles: a catalyst for low-temperature carbon monoxide oxidation," Journal of the Chemical Society, Chemical Communications, 1995, 2283 (1995).

[23] Jacek, M., David, B., Jong-Sung, Y., Marek, D., Jeong Yeon, K., and Larry, K., "Conduction electron paramagnetic resonance of metal nanoparticles in AlMCM-41 aluminosilica mesoporous molecular sieves," 3, 1705 (2001).

[24] Yang, P., Zhao, D., Margolese, D. I., Chmelka, B. F., and Stucky, G. D., "Block Copolymer Templating Syntheses of Mesoporous Metal Oxides with Large Ordering Lengths and Semicrystalline Framework," Chemistry of Materials, 11, 2813 (1999).

[25] Lee, K., Lee, S., and Cheon, J., "Size-controlled synthesis of Pd nanowires using a mesoporous silica template via chemical vapor infiltration," Advanced Materials, 13, 517 (2001).

[26] Okumura, M., Nakamura, S., Tsubota, S., Nakamura, T., Azuma, M., and Haruta, M., "Chemical vapor deposition of gold on $\mathrm{A} 12 \mathrm{O} 3, \mathrm{SiO} 2$, and $\mathrm{TiO} 2$ for the oxidation of $\mathrm{CO}$ and of H2," Catalysis Letters, 51, 53 (1998). 
[27] Zhu, J., Kónya, Z., Puntes, V. F., Kiricsi, I., Miao, C. X., Ager, J. W., Alivisatos, A. P., and Somorjai, G. A., "Encapsulation of Metal (Au, Ag, Pt) Nanoparticles into the Mesoporous SBA-15 Structure," Langmuir, 19, 4396 (2003).

[28] Kónya, Z., Puntes, V. F., Kiricsi, I., Zhu, J., Alivisatos, P., and Somorjai, G. A., "Novel Two-Step Synthesis of Controlled Size and Shape Platinum Nanoparticles Encapsulated in Mesoporous Silica," Catalysis Letters, 81, 137 (2002).

[29] Zhao, D., Yang, P., Melosh, N., Feng, J., Chmelka, B. F., and Stucky, G. D., "Continuous Mesoporous Silica Films with Highly Ordered Large Pore Structures," Advanced Materials, 10, 1380 (1998).

[30] Anderson, J. R., Structure of Metallic Catalysis, New York, Academic Press, (1975).

[31] Yang, C.-M., Sheu, H.-S., and Chao, K.-J., "Templated Synthesis and Structural Study of Densely Packed Metal Nanostructures in MCM-41 and MCM-48," Advanced Functional Materials, 12, 143 (2002).

[32] Yang, C.-M., Liu, P.-H., Ho, Y.-F., Chiu, C.-Y., and Chao, K.-J., "Highly Dispersed Metal Nanoparticles in Functionalized SBA-15," Chemistry of Materials, 15, 275 (2002).

[33] Rioux, R. M., Song, H., Hoefelmeyer, J. D., Yang, P., and Somorjai, G. A., "HighSurface-Area Catalyst Design: Synthesis, Characterization, and Reaction Studies of Platinum Nanoparticles in Mesoporous SBA-15 Silica†," The Journal of Physical Chemistry B, 109, 2192 (2004).

[34] Zhu, H., Lee, B., Dai, S., and Overbury, S. H., "Coassembly Synthesis of Ordered Mesoporous Silica Materials Containing Au Nanoparticles," Langmuir, 19, 3974 (2003).

[35] Dag, Ö., Samarskaya, O., Coombs, N., and Ozin, G., "The synthesis of mesostructured silica films and monoliths functionalised by noble metal nanoparticles," Journal of Materials Chemistry, 13, 328 (2003).

[36] Krawiec, P., Kockrick, E., Simon, P., Auffermann, G., and Kaskel, S., "PlatinumCatalyzed Template Removal for the in Situ Synthesis of MCM-41 Supported Catalysts," Chemistry of Materials, 18, 2663 (2006).

[37] Chen, C.-Y., Li, H.-X., and Davis, M. E., "Studies on mesoporous materials: I. Synthesis and characterization of MCM-41," Microporous Materials, 2, 17 (1993).

[38] M. Grun, I. L., K. Unger, Adv. Mater., 9, (1997).

[39] G. Buchel, R. D., P.L. Llewellyn, J. Rouquerol, J. Mater. Chem., 11, (2001). 
[40] Kuila, D., Tatineni, B., Islam, A., Basova, Y., Rahman, A., Rahman, M., Islam, S., Ilias, S., Taylor, J., and King, J., "Novel nanocatalysts for hydrogen production," Prepr. Symp. - Am. Chem. Soc., Div. Fuel Chem., 54, 1072 (2009).

[41] Solovyov, L., Belousov, O., Shmakov, A., Zaikovskii, V., Joo, S., Ryoo, R., Haddad, E., Gedeon, A., and Kirik, S., "X-ray diffraction analysis of mesostructured materials by continuous density function technique," (2003)

[42] Brinker, C. and Scherer, G., Sol-gel science: the physics and chemistry of sol-gel processing, Academic Pr, (1990).

[43] Brunauer, S., Deming, L. S., Deming, W. E., and Teller, E., "On a Theory of the van der Waals Adsorption of Gases," Journal of the American Chemical Society, 62, 1723 (1940).

[44] Sing, S. J. G. K. S. W., Surface Area and Porosity,2nd ed., New York, Academic Press, (1982).

[45] Grubert, G., Rathouský, J., Schulz-Ekloff, G., Wark, M., and Zukal, A., "Reducibility of vanadium oxide species in MCM-41," Microporous and Mesoporous Materials, 22, 225 (1998).

[46] Kong, Y., Jiang, S.-Y., Wang, J., Wang, S.-S., Yan, Q.-J., and Lu, Y.-N., "Synthesis and characterization of Cu-Ti-MCM41," Microporous and Mesoporous Materials, 86, 191 (2005).

[47] Tichit, D., Bennani, M. N., Figueras, F., and Ruiz, J. R., "Decomposition Processes and Characterization of the Surface Basicity of Cl- and CO32- Hydrotalcites," Langmuir, 14, 2086 (1998).

[48] Vondrova, M., Klimczuk, T., Miller, V. L., Kirby, B. W., Yao, N., Cava, R. J., and Bocarsly, A. B., "Supported Superparamagnetic Pd/Co Alloy Nanoparticles Prepared from a Silica/Cyanogel Co-gel," Chemistry of Materials, 17, 6216 (2005).

[49] Vondrova, M., Majsztrik, P. W., Gould, S., and Bocarsly, A. B., "Solid-State Chemistry in a Microwave Oven: Preparation of $\mathrm{Pd} / \mathrm{Co}$ Alloy from Cyanogel Coordination Polymers," Chemistry of Materials, 17, 4755 (2005).

[50] Park, S., Kim, B., Selvaraj, M., and Lee, T., "Synthesis and Characterization of Mesoporous Ce-Mn-MCM-41 Molecular Sieves," J. Ind. Eng. Chem, 13, 637 (2007). 